\title{
Predicting Smoke and Carbon Monoxide Detector Response in the Ceiling Jet in the Presence of a Smoke Layer
}

\author{
William D. Davis \\ Thomas G. Cleary \\ Michelle K. Donnelly \\ Samuel D. Hellerman
}



NISTIR 6976

\title{
Predicting Smoke and Carbon Monoxide Detector Response in the Ceiling Jet in the Presence of a Smoke Layer
}

\author{
William D. Davis \\ Thomas G. Cleary \\ Michelle Donnelly \\ Samuel Hellerman
}

Building and Fire Research Laboratory

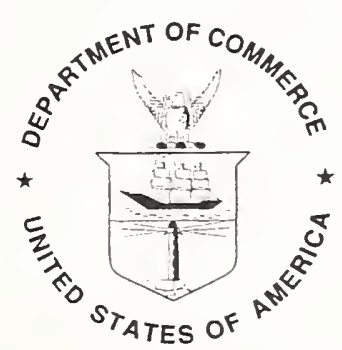

U.S. DEPARTMENT OF COMMERCE

Donald L. Evans, Secretary TECHNOLOGY ADMINISTRATION

Phillip J. Bond, Under Secretary of Commerce for Technology NATIONAL INSTITUTE OF STANDARDS AND TECHNOLOGY Arden L. Bement, Jr., Director 



\title{
Predicting Smoke and Carbon Monoxide Detector Response in the Ceiling Jet in the Presence of a Smoke Layer
}

William D. Davis, Thomas Cleary, Michelle Donnelly, and Samuel Hellerman

\begin{abstract}
An algorithm for predicting smoke or carbon monoxide concentration in the ceiling jet in the presence of a smoke layer is developed. The analysis will be restricted to fires that produce turbulent plumes and can be represented by axisymmetric point sources. The predictions of the algorithm for smoke and carbon monoxide are compared with experiments. Once the smoke or carbon monoxide concentration in the ceiling jet is predicted, the activation times for detectors can be calculated using a model for detector activation.
\end{abstract}

\section{Introduction}

Predicting smoke detector response to a growing fire requires calculating the time dependent evolution of the smoke concentration in the ceiling jet. Typically, the temperature rather than the smoke concentration is used to predict smoke detector response due to the availability of correlations that give ceiling jet temperature ${ }^{1}$ and the assumption that smoke concentration can be related to ceiling jet temperature ${ }^{2,3}$. Using temperature to predict smoke detector activation ignores differences in the production of smoke by burning materials that may completely invalidate a temperature/smoke prediction correlation.

There have been efforts to use computational fluid dynamic (CFD) methods to calculate the smoke concentration in the ceiling jet and with the increased computer power available today, these methods are becoming practical ${ }^{4,5}$. However, there is still a need for an algebraic correlation that would yield smoke concentration in the ceiling jet and not require substantial computer power to obtain the solution. Early work along this line can be found in Alpert's paper on the ceiling jet that resulted in the successful unconfined ceiling jet temperature and velocity correlations ${ }^{6}$ in use today. Later, Yamauchi ${ }^{7}$ extended Alpert's work to calculate the smoke concentration and smoke detector activation in the ceiling jet when a hot layer was developing. Yamauchi's method required the solution of a set of differential equations in order to define the ceiling jet properties as well as a zone model to define the depth and temperature of the hot layer.

In this paper, an algebraic correlation for smoke or carbon monoxide concentration in the ceiling jet in the presence of a smoke layer will be developed. The analysis will be restricted to fires that produce turbulent plumes and can be represented by axisymmetric point sources. Once the smoke or carbon monoxide concentration in the ceiling jet is predicted, the activation times for detectors can be calculated using a model for detector activation. 


\section{Theory}

The development of a ceiling jet algorithm requires the solution of three separate problems. The first problem is to model the smoke plume as it rises from the fire to the ceiling. The second problem is to model the turning point as the plume flow impinges on the ceiling and turns to form the ceiling jet. The third problem is to model the ceiling jet flow as it slows and deepens in its movement across the ceiling.

\section{The Plume Region}

In order to develop an algebraic correlation for the smoke or gas concentration in the plume, the following assumptions must be made in order to simplify the equations. The fire will be represented by a point source and assumed to be axisymmetric. The zone model approximation of homogeneous temperature and particle densities in each layer is assumed. Gaussian shapes in the radial direction will represent the velocity, temperature, and smoke profiles in the plume. All air entrained into the plume below the smoke layer interface will be considered to be smoke or gas free.

The mass flux of smoke or gas in a radially symmetric plume can be written as

$$
\dot{m}_{s}(z)=\int_{0}^{\infty} C_{s p}(r, z) u_{z}(r, z) 2 \pi r d r
$$

where $C_{s p}(r, z)$ is the scalar representing the mass concentration of smoke particles or a gaseous combustion product such as $\mathrm{CO}$ in the plume, $u_{z}(r, z)$ is the plume velocity, $r$ is the radial distance from the plume centerline and $z$ is the height above the fire source. The assumed Gaussian profiles for the scalar mass concentration in the plume and the plume velocity are,

$$
\begin{aligned}
& C_{s p}(r, z)=C_{s p 0}(z) e^{-\left(r^{2} / \lambda^{2} \sigma^{2}\right)} \\
& u_{z}(r, z)=u_{z m}(z) e^{\left(-r^{2} / \sigma^{2}\right)}
\end{aligned}
$$

where $C_{s p 0}$ is the scalar mass concentration for the plume centerline, $u_{z m}$ is the plume centerline velocity, $\lambda \sigma$ is the $1 / e$ width of the plume scalar profile and $\sigma$ is the $1 / e$ width of the velocity profile. It has been assumed that the smoke or gaseous combustion product profile in the plume scales with the temperature profile in the plume ${ }^{2}$. Integrating equation 1 and solving for the maximum scalar mass concentration at the plume centerline gives 


$$
C_{s p 0}(z)=\frac{\dot{m}_{s}(z)\left(\frac{\lambda^{2}+1}{\lambda^{2}}\right)}{u_{z n}(z) \pi \sigma^{2}}
$$

The plume correlations developed by Heskestad ${ }^{8}$ for plume radius and plume centerline velocity $b$ and $u_{z} m$, where $b$ is the plume radius where the temperature has dropped to 0.5 the plume centerline temperature $T(z)$ and $z_{0}$ is the location of the virtual point source with respect to the fire surface, are given by

$$
\begin{aligned}
& b(z)=C_{1}\left(\frac{T(z)}{T_{\infty}}\right)^{1 / 2}\left(z-z_{0}\right) \\
& u_{z m}(z)=\frac{3.4\left(\frac{g}{c_{p} \rho_{\infty} T_{\infty}}\right)^{1 / 3}\left(1-\chi_{r}\right)^{1 / 3} \dot{Q}^{1 / 3}}{\left(z-z_{0}\right)^{1 / 3}}
\end{aligned}
$$

The plume centerline scalar mass concentration then becomes

$$
C_{s p o}(z)=\frac{\left(\frac{\lambda^{2}+1}{\lambda^{2}}\right) \dot{m}_{s}}{3.4\left(\frac{g}{c_{p} \rho_{\infty} T_{\infty}}\right)^{1 / 3}\left(1-\chi_{r}\right)^{1 / 3} \dot{Q}^{1 / 3} \pi(1.201)^{2} C_{1}^{2} \frac{T(z)}{T_{\infty}}\left(z-z_{0}\right)^{5 / 3}}
$$

where the distance $\mathrm{z}-\mathrm{z}_{0}$ is the distance above the virtual point source. The constant $C_{l}=0.12$, and the plume radius for the temperature to drop to $1 / e$ of its centerline value, assuming a Gaussian distribution, $\sigma=1.201 \mathrm{~b}$ are experimentally determined.

The mass flux of the scalar produced by the fire may be calculated using the data provided by Tewarson ${ }^{9}$

$$
\dot{m}_{s}=Y_{s} \frac{\dot{Q}}{h_{c}}
$$


where $h_{c}$ is the heat of combustion, $Y_{s}^{+}$is the scalar yield fraction and $Q$ is the heat release rate. The plume centerline scalar concentration is given by

$$
C_{s p 0}(z)=\frac{D \dot{Q}^{* 2 / 3}}{\frac{T(z)}{T_{\infty}}}
$$

where

$$
D=\frac{Y_{s}\left(\frac{\lambda^{2}+1}{\lambda^{2}}\right) \rho_{\infty} c_{p} T_{\infty}}{3.4 h_{c} \pi\left(1-\chi_{r}\right)^{1 / 3}(1.201)^{2} C_{1}^{2}}
$$

$$
\dot{Q}^{*}=\frac{\dot{Q}}{\rho c_{p} T_{\infty} g_{\infty}^{2} Z^{5 / 2}}
$$

and $Z=z-z_{0}$. The temperature ratio, $T(z) / T_{\infty}$, can be evaluated using Heskestad 's correlations for plume centerline temperature excess ${ }^{8}, T(z)-T_{\infty}$, and location of the virtual point source.

$$
\begin{aligned}
& T(z)-T_{\infty}=9.1\left(\frac{T_{\infty}}{g c_{p}^{2} \rho_{\infty}^{2}}\right)^{1 / 3} \frac{\left(1-\chi_{r}\right)^{2 / 3} \dot{Q}^{2 / 3}}{\left(z-z_{0}\right)^{5 / 3}} \\
& z_{0}=-1.02 d+0.083 \dot{Q}^{2 / 5}
\end{aligned}
$$

where $d$ is the fire diameter. Hence,

$$
\frac{T(z)}{T_{\infty}}=1+K \dot{Q}^{22 / 3}
$$

${ }^{+}$Smoke yield fraction (in grams of smoke produced per gram of fuel burned) is tabulated in many literature sources. Smoke yield fraction can also be estimated by dividing specific extinction area (from the cone calorimeter ASTM 1354) by $8.71 \times 10^{3} \mathrm{~m}^{2} / \mathrm{kg}^{10}$. 
where $K=9.1\left(1-\chi_{r}\right)^{2 / 3}$.

The plume centerline scalar concentration becomes

$$
C_{s p 0}\left(\dot{Q}^{*}\right)=\frac{D \dot{Q}^{* 2 / 3}}{\left(1+K \dot{Q}^{* 2 / 3}\right)}
$$

When a smoke layer is present, the plume centerline scalar concentration must be corrected for the entrained scalar as the smoke plume passes through the smoke layer. This can be approximated by replacing the fire with a substitute source and requiring that the plume produced by the substitute source is entirely in the smoke layer. The location and strength of the substitute source may be determined by requiring that the scalar mass flux at the layer interface be conserved and that the plume centerline scalar concentration be continuous across the layer interface. The requirement that the plume centerline scalar concentration be continuous across the layer interface is expressed by

$$
C_{s p 01}=C_{s p 02}+C_{L}
$$

where $C_{L}$ is the scalar concentration in the layer and the subscripts 1 and 2 refer to the plume centerline scalar concentration at the layer interface in the lower layer and the plume centerline scalar concentration in the smoke layer at the equivalent layer interface height. Using equation 15 , the substitute source $Q_{2}{ }^{*}$ is

$\dot{Q}_{2}^{*}=\left[\frac{D \dot{Q}_{1}^{* 2 / 3}-C_{L}\left(1+k \dot{Q}_{1}^{* 2 / 3}\right)}{D+C_{L} K\left(1+K \dot{Q}_{1}^{* 2 / 3}\right)}\right]^{3 / 2}$

The conservation of scalar mass flux at the boundary may be expressed by

$$
\int_{0}^{\infty} C_{p 1}(r, z) u_{1}(r, z) 2 \pi r d r=\int_{0}^{\infty}\left(C_{p 2}(r, z)+C_{L}\right) u_{2}(r, z) 2 \pi r d r
$$

Substituting equations 2 and 3 into 18 and integrating yields with the substitution of equations 5,6 , and 14 the location of the substitute source with respect to the layer interface.

$$
Z_{2}=Z_{1}\left[\frac{\dot{Q}_{1}^{*}}{\left(\dot{Q}_{2}^{*}+\frac{\left(\lambda^{2}+1\right)}{\lambda^{2}} \frac{C_{L}}{D}\left(1+K \dot{Q}_{2}^{* 2 / 3}\right) \dot{Q}_{2}^{* 1 / 3}\right)}\right]^{2 / 5}
$$


The requirement that the distance to the ceiling from the interface must be identical for both calculations is satisfied by

$$
H_{2}-Z_{2}=H_{1}-Z_{1}
$$

The plume centerline scalar concentration at the ceiling can then be calculated using the substitute source by

$$
C_{s p 0}=\frac{D \dot{Q}_{2}^{* 2 / 3}\left(\frac{Z_{2}}{H_{2}}\right)^{5 / 3}}{\left(1+K \dot{Q}_{2}^{* 2 / 3}\left(\frac{Z_{2}}{H_{2}}\right)^{5 / 3}\right)}+C_{L}
$$

\section{The Turning Region}

The next step is to obtain the smoke or gas concentration in the ceiling jet using the calculated scalar concentration in the plume. Following Alpert's derivation ${ }^{6}$ and equating the mass flux in the plume to mass flux at the start of the ceiling jet, Yamauchi ${ }^{7}$ developed an equation which related the maximum smoke concentration in the plume at the ceiling, $C_{s p 0}$ to the average smoke concentration at the start of the ceiling jet, $C_{s, a v e}$ in terms of the Gaussian width ratio $\lambda$ for the velocity and temperature profiles in the plume. Assuming that the same ratios work for gas as well as smoke, the scalar concentration for gas or smoke is given by

$$
C_{s, a v e}=\frac{\lambda^{2}}{\lambda^{2}+1}\left(C_{s p 0}-C_{L}\right)+C_{L}
$$

Assuming that the scalar concentration of gas or smoke in the unconfined ceiling jet can be represented by a half Gaussian profile, the maximum scalar concentration in the ceiling jet, $C_{s}$ is given by

$$
C_{s 0}(r=0.18 H)=\sqrt{2} \frac{\lambda^{2}}{1+\lambda^{2}}\left(C_{s p 0}(H)-C_{L}\right)+C_{L}
$$

where $\lambda^{2}=1.157, \mathrm{r}$ is the radial distance from the plume centerline and $H$ is the distance from the surface of the fire to the ceiling. 


\section{The Ceiling Jet Region}

The scalar concentration of gas or smoke in the ceiling jet may be calculated from the scalar mass flux equation by integrating over the vertical dimension, $y$.

$$
\frac{1}{r} \frac{d}{d r} \int_{0}^{\infty}\left[\left(C_{s}(r, y)-C_{L}\right) v(r, y) r d y\right]=0
$$

It has been assumed that the density of the scalar concentration in the layer is constant, independent of position. The resulting spatial averages yield the average scalar concentration in the ceiling jet as a function of $r$ as

$$
C_{s}(r)=\left(C_{s}\left(r_{e}\right)-C_{L}\right) \frac{r_{e} v_{e} h_{e}}{r v h}+C_{L}
$$

where the subscript "e" represents the location where the ceiling jet forms $\left(r_{e}=0.18 H\right), h$ is the average thickness of the ceiling jet, $v$ is the average ceiling jet velocity and $r$ is the radial distance from plume center. Using Alpert's correlation for the maximum ceiling jet velocity

$$
v=\frac{0.195 \dot{Q}^{1 / 3} H^{1 / 2}}{r^{5 / 6}}
$$

and fitting Alpert's calculation ${ }^{6}$ for ceiling jet thickness to a power law $\left(h / H \sim(r / H)^{0.4}\right.$, $0.18 H<r<2.0 H$ ), the maximum scalar concentration in the ceiling jet is given by

$$
C_{s 0}(r)=\left(C_{s 0}\left(r_{e}\right)-C_{L}\right)\left[\frac{r_{e}}{r}\right]^{.57}+C_{L}
$$

where the ceiling jet is assumed to be a half Gaussian. Replacing $C_{s} 0\left(r_{e}\right)$ using Equations 21 and 23 , the maximum scalar concentration at a radial location from plume center in the ceiling jet for $r>0.18 \mathrm{H}$ is given by

$$
C_{s 0}(r)=\frac{\sqrt{2}\left(\frac{\lambda^{2}}{\lambda^{2}+1}\right) D \dot{Q}_{2}^{* 2 / 3}\left(\frac{Z_{2}}{H_{2}}\right)^{5 / 3}\left(\frac{r_{e}}{r}\right)^{.57}}{\left(1+k \dot{Q}_{2}^{* 2 / 3}\left(\frac{Z_{2}}{H_{2}}\right)^{5 / 3}\right)}+C_{L}
$$


With the appropriate product yield fraction in equations 8 and 10 , equation 28 predicts the concentration of smoke, $\mathrm{CO}$, or other combustion product in the ceiling jet.

\section{Experiment}

Experiments were conducted to test the capability of the algorithm to predict $\mathrm{CO}$ and smoke concentration in the ceiling jet. The experiments were conducted in a room with floor dimensions of $3.15 \mathrm{~m}$ by $3.02 \mathrm{~m}$. A sand burner was centered in the room with the height between the top of the burner and the ceiling being either $2.19 \mathrm{~m}, 1.50 \mathrm{~m}$ or $0.77 \mathrm{~m}$. Two burner geometries were used. The first burner was round with a diameter of $0.085 \mathrm{~m}$ while the second burner was square with an effective diameter of $0.194 \mathrm{~m}$. The burners were operated with heat release rates sufficient that the flame heights should scale as the $2 / 5$ power of the heat release rate (HRR). ${ }^{11}$ The flat, smooth ceiling was made up of acoustic ceiling tile. The walls of the room were constructed of glazed cinderblocks except for one that was constructed of ceiling tile.

Instrumentation included thermocouples, $\mathrm{CO}$ detectors, a laser extinction meter to measure obscuration and a tapered-element oscillating microbalance (TEOM) to measure smoke mass concentration. Temperature measurements in the ceiling jet were conducted using bare bead $0.076 \mathrm{~cm}$ thermocouples positioned $1 \mathrm{~cm}$ below the ceiling at radial positions shown in figure 1 . A thermocouple tree located $60 \mathrm{~cm}$ from plume center with thermocouples located vertically below the ceiling at 1.0,3.0,6.0,12.0, 24.0,36.0,50.0,75.0 and $100.0 \mathrm{~cm}$ were used to measure the depth of the ceiling jet and the temperature in the smoke layer. An aspirated thermocouple was used to check the impact of radiation on the bare bead thermocouples.

The $\mathrm{CO}$ measurements were conducted using electrochemical cells removed from residential $\mathrm{CO}$ detectors. The carbon monoxide sensors inside the detectors consisted of electrochemical cells with terminals connected to a resistor. The voltage drop across the resistor increased linearly when $\mathrm{CO}$ was detected. The electrochemical cells were calibrated by exposing them to a controlled amount of $\mathrm{CO}$ gas inside the fire emulator/detector evaluator tunnel (FE/DE) ${ }^{12}$. The detectors were placed in the empty evaluation tunnel and the voltage reading corresponding to 0 volume fraction of $\mathrm{CO}$ was recorded for 120 seconds. Then, a mixture of $\mathrm{CO}$ gas and air was allowed to flow into the tunnel. The mixture had a constant volume fraction equal to $30 \mathrm{x}$ $10^{-6}$ of CO, which was verified by a (Siemens Ultramat*) gas analyzer using IR absorption to measure the gas concentration. The $\mathrm{CO}$ mixture flowed until the electrochemical cells reached a steady voltage, at which point the $\mathrm{CO}$ mixture continued to flow while 60 seconds of voltage data was recorded. The $\mathrm{CO}$ flow was then turned off and the $\mathrm{CO}$ cleared from the tunnel to confirm that the cells would return to their original voltages. A mean value for the voltage at a volume fraction of $\mathrm{CO}$ of 0 and $30 \times 10^{-6}$ was calculated for each cell. These two points were used to scale the $\mathrm{CO}$ from the voltage, assuming a linear relationship, which had been determined in earlier testing. The housing surrounding the $\mathrm{CO}$ detector would accept flow between the ceiling and $3.2 \mathrm{~cm}$ beneath the ceiling. There were also small vents located at the bottom of the housing about $8.9 \mathrm{~cm}$ beneath the ceiling. Figure 1 provides the layout for the

* The identification of any commercial product or trade name does not imply endorsement or recommendation by the National Institute of Standards and Technology. 
detectors with detectors one through six mounted on the ceiling and detector seven mounted at $1 / 3$ of the distance between the burner and the ceiling. Detectors 3 and 5 were located along the same radius and were used to check the radial dependence of the $\mathrm{CO}$ volume fraction.

Smoke obscuration measurements were conducted using a helium-neon laser mounted such that the exposed laser beam was located $1.0 \mathrm{~m}$ from the plume centerline, $6.35 \mathrm{~cm}$ beneath the ceiling and had a path length of $0.5 \mathrm{~m}$ as shown in figure 1 . By measuring the decrease in intensity of the beam, the smoke density is deduced from the light extinction coefficient using the extinction coefficient per unit mass, $8.71 \mathrm{~m}^{2} / \mathrm{g}^{10}$.

A tapered element oscillating microbalance (TEOM) was used as a second method of measuring smoke concentration. The sampling tube for the TEOM was positioned $4.4 \mathrm{~cm}$ beneath the ceiling and $1.0 \mathrm{~m}$ from the plume centerline.

Two fuels, propane $\left(\mathrm{C}_{3} \mathrm{H}_{8}\right)$ and propene $\left(\mathrm{C}_{3} \mathrm{H}_{6}\right)$, were used for the experiments. Values for the heat of combustion, radiation fraction, smoke yield and $\mathrm{CO}$ yield for these fuels are taken from the literature and tabulated below ${ }^{913141516}$. The calculations were done using the values of Tewarson ${ }^{9}$ or using values obtained from the NIST cone calorimeter. Differences in the yield fractions and heat of combustion enter the calculations linearly. Differences in radiation fraction will have a small and nonlinear impact on the calculations as the depth of the smoke layer will be impacted as well as values in the correlation developed above.

Table 1. Yield fractions for smoke and $\mathrm{CO}$, radiation fraction, and heat of combustion for propane and propene.

\begin{tabular}{|c|c|c|c|c|}
\hline Ref \# & $\begin{array}{c}\mathbf{Y}_{\mathrm{s}} \\
\text { Propane/Propene } \\
(\mathrm{g} / \mathrm{g})\end{array}$ & $\begin{array}{c}\mathbf{Y}_{\mathrm{co}} \\
\text { Propane/Propene } \\
(\mathrm{g} / \mathrm{g})\end{array}$ & $\begin{array}{c}\text { Radiation Fract. } \\
\text { Propane/Propene }\end{array}$ & $\begin{array}{c}\text { Heat of Comb. } \\
\text { Propane/Propene } \\
\mathrm{kJ} / \mathrm{g}\end{array}$ \\
\hline 9 & $\mathbf{0 . 0 2 4 / 0 . 0 9 5}$ & $\mathbf{0 . 0 0 5 / 0 . 0 1 7}$ & $\mathbf{0 . 2 7 / 0 . 3 2}$ & $\mathbf{4 3 . 7 / 4 0 . 5}$ \\
\hline 13 & $\mathbf{0 . 0 2 1 / 0 . 0 7 4}$ & & & \\
\hline 14 & $\mathbf{0 . 0 1 0 / 0 . 0 6 9}$ & & $\mathbf{0 . 2 8 / 0 . 4 0}$ & \\
\hline 15 & & & $0.27 / 0.38$ & \\
\hline 16 & $\mathbf{0 0 4 5 / x}$ & & $0.27 / \mathrm{x}$ & \\
\hline
\end{tabular}




\section{Analysis}

The predictive capability of the ceiling jet algorithm is compared with measurements of $\mathrm{CO}$ and smoke in the ceiling jet. CO measurements were also conducted in the smoke layer. The locations of the ceiling jet and layer interface were determined using the temperature measurements from the thermocouple tree located $60 \mathrm{~cm}$ from the fire center. The ceiling jet can be identified as the region near the ceiling in which the temperature is about uniform. For the experiments described in this paper, it can be seen from figs. 2 through 6 that the ceiling jet boundary develops rapidly and extends down to between 6 and $12 \mathrm{~cm}$ beneath the ceiling in all cases.

\section{CO Analysis}

The $\mathrm{CO}$ measurements in the ceiling jet and smoke layer were made using commercial $\mathrm{CO}$ detectors. The response characteristics of the $\mathrm{CO}$ detectors must be known in order to compare the detector measurements with the predictions of the ceiling jet algorithm. Since the fires used in the experiment were small, delay times must also be included to account for the time for the ceiling jet flow to reach the detector and the time required to form a smoke layer. The $2.19 \mathrm{~m}$ propene experiment will be used to demonstrate the importance of these factors.

Figure 7 provides a comparison of the ceiling jet algorithm predictions with the experimental data. Transit times and detector characteristics are not included in the modeling. The zone model calculations assume that the ceiling jet is fully formed and that the layer begins to develop at the start of the experiment. The zone model $\mathrm{JET}^{17}$ was used to determine the layer height and temperature for the calculations. The $\mathrm{CO}$ volume fraction for the layer was calculated by integrating the $\mathrm{CO}$ production over time and dividing by the layer volume. It was assumed that there was no loss of $\mathrm{CO}$ from the layer. As seen in figure 7 , ignoring the transit times as well as the detector characteristics produce a substantial over prediction of the measured $\mathrm{CO}$ volume fraction.

The detector response time for the layer and layer delay time can be included in the calculation by using the measured $\mathrm{CO}$ volume fraction for the layer in the calculation as shown in figure 8 . Since the zone model approximation is still used to calculate the ceiling jet volume fraction, the calculated value for the ceiling jet starts at a nonzero value that remains constant until the smoke layer begins to form. The measured value for the ceiling jet begins to rise at $30 \mathrm{~s}$ after the start of the experiment and approaches the calculated value for the ceiling jet. At $60 \mathrm{~s}$ after the start of the experiment, the $\mathrm{CO}$ detector in the layer begins to respond which marks the beginning of the impact of the smoke layer on the ceiling jet. Using the measured value of the layer $\mathrm{CO}$ volume fraction, the calculated value of the $\mathrm{CO}$ volume fraction in the ceiling jet is nearly identical to the measured value.

In order to model the response of the $\mathrm{CO}$ detectors in the ceiling jet and layer, an experimental effort $^{18}$ was undertaken to develop a detector algorithm. The FE/DE was used to produce a constant velocity, constant CO concentration environment. Smoldering cotton wicks were used to supply the constant source of $\mathrm{CO}$. The detector was isolated from the $\mathrm{CO}$ environment by placing a tight fitting can over it. Once the $\mathrm{CO}$ concentration near the detector was steady, the 
can was removed and the detector response measured. The amount of time required for the detector to begin to respond once it was exposed to $\mathrm{CO}$ was quite short and taken to be $1.0 \mathrm{~s}$. The response of the detector could be simulated using the fitting function $y=1-(1+t / \tau) e^{-t / \tau}$. This equation is consistent with a two-step diffusion process with the time constant $\tau$ being the same for each step. The gas flow velocity was varied from $0.042 \mathrm{~m} / \mathrm{s}$ to $0.22 \mathrm{~m} / \mathrm{s}$ with the detector's value of $\tau$ varying from $19.7 \mathrm{~s}$ to $27.9 \mathrm{~s}$ as the flow velocity decreased.

The ceiling jet and detector algorithms for smoke and gas were added to the zone model JET and the model predictions were tested against the data collected with the $\mathrm{CO}$ detectors. The general equation set used to represent the two-step diffusion process for the detectors is

$$
\begin{aligned}
& \frac{d X(t)}{d t}=\left[X_{e}(t-\delta \tau)-X(t)\right] / \tau \\
& \frac{d X_{s}(t)}{d t}=\left[X(t)-X_{s}(t)\right] / \tau \\
& \delta \tau=a u_{e}^{-c} \\
& \tau=b u_{e}^{-d}
\end{aligned}
$$

$\mathrm{X}(\mathrm{t})$ is the smoke or gas mass density in the sensing chamber, $X_{e}$ is the smoke or gas mass density at the location of the detector, $X_{s}$ is the gas mass density at the electrochemical sensor, $\mathrm{u}_{\mathrm{e}}$ is the flow velocity outside of the detector housing, $\delta \tau$ is the dwell or offset time for the flow to travel through the detector to the sensing chamber, $\tau$ is the mixing time in the sensing chamber, and a, b, c, and d are determined from the response time fits of the detector. For flow velocities above $0.1 \mathrm{~m} / \mathrm{s}, \delta \tau$ and $\tau$ become less sensitive to velocity variations for the detectors tested and can be treated as constants, which was the case for these tests.

The CO mass fraction produced by the small burner was measured using the NIST cone calorimeter and found to be 0.0136 . That is slightly smaller than the value 0.017 given in table 1. The value, 0.0136 , was used in the calculations.

Two propene experiments that use the small burner with a HRR of $2.5 \mathrm{KW}$ and have ceiling heights of $1.5 \mathrm{~m}$ and $2.19 \mathrm{~m}$ were modeled using JET. Due to the changing CO concentrations in the ceiling jet and layer, the $\mathrm{CO}$ detectors were modeled using the two first order differential equations that simulated the fitting function for constant $\mathrm{CO}$ exposure found for the detector. Time constants of $19.7 \mathrm{~s}$ and $27.9 \mathrm{~s}$ were used to simulate the response of the detector in the ceiling jet and layer respectively. Transit times at the beginning of the experiment were measured using the response of thermocouples located at the positions of the $\mathrm{CO}$ detectors in the ceiling jet and layer. For the $2.19 \mathrm{~m}$ experiment, the transit times were $4 \mathrm{~s}$ to the ceiling jet $\mathrm{CO}$ detector at $0.6 \mathrm{~m}$ and $28 \mathrm{~s}$ to $\mathrm{CO}$ detector 7 located where the layer should form. For the 1.5 $\mathrm{m}$ experiment, the measured transit times were $3 \mathrm{~s}$ and $39 \mathrm{~s}$ to these detector positions. The $39 \mathrm{~s}$ time was difficult to estimate as the temperature increase in the layer was quite small initially at the position of the $\mathrm{CO}$ detector and could be confused with the slow temperature rise of the 
thermocouples responding to radiation from the fire. Transit times were also estimated using the velocity equations for the plume and ceiling jet, equations 6 and 26, with the time to the ceiling jet detector and layer detector calculated integrating over the path using $t=\int d x / v$ where $v$ is the velocity. It was assumed that the return flow velocity could be roughly approximated using equation 26 over these distances. The resulting calculations gave values of $2 \mathrm{~s}$ and $39 \mathrm{~s}$ for the 2.19 experiment and $1 \mathrm{~s}$ and $45 \mathrm{~s}$ for the $1.5 \mathrm{~m}$ experiment. The $39 \mathrm{~s}$ and $45 \mathrm{~s}$ times are the times for the ceiling jet to flow from $0.2 \mathrm{H}$ to the wall and back to the plume center rather than to the $0.6 \mathrm{~m}$ position.

The transit times to the ceiling jet detector and layer detector used in the modeling were $3 \mathrm{~s}$ and $39 \mathrm{~s}$ for the $1.5 \mathrm{~m}$ experiment and $4 \mathrm{~s}$ and $28 \mathrm{~s}$ for the $2.19 \mathrm{~m}$ experiment. The formation of the layer was delayed in the model using the layer transit time. The layer begins to form once the ceiling jet strikes the walls and begins to turn back toward the plume. The ceiling jet conditions will be impacted by this flow once the flow has reached the vicinity of the plume.

Figures 9 and 10 provide the results of the simulations using JET and are compared with the measured values for the $\mathrm{CO}$ volume fraction using detectors in the ceiling jet and layer at $0.6 \mathrm{~m}$ from the plume centerline. A small baseline displacement of roughly $-1.0 \times 10^{-6}$ in the volume fraction occurred for the ceiling jet detector when the ceiling jet flow interacted with the detector. The zero level for both figures was taken as the bottom of the dip. If the baseline returned to its normal location after the initial thermal insult, the volume fraction shown on the curves for the ceiling jet measurement should be decreased by $1.0 \times 10^{-6}$. No baseline shift was observed for the detectors in the smoke layer.

The model predictions follow the increasing trend of the measured volume fraction for the first $80 \mathrm{~s}$ of the experiment. At later times the measured values rise more slowly than the predicted values. The predicted and measured values of $\mathrm{CO}$ volume fraction agree to within approximately $25 \%$ or better over the experimental range. The fall-off in the agreement between the model and experiments at the later times could result from the slow venting of the smoke layer as the model did not include losses in the calculations.

Comparisons of the measured values of $\mathrm{CO}$ using the large burner with a fire size of $7.6 \mathrm{~kW}$ and ceiling heights of $1.5 \mathrm{~m}$ and $2.19 \mathrm{~m}$ are given in figures 11 and 12 . The CO mass yield measured for the small propene burner was used to represent the large propene burner, as the large burner was too big to be tested in the cone calorimeter. The baseline displacement for the ceiling jet detectors were larger for these experiments with two curves given for the ceiling jet volume fraction, one that uses the baseline prior to the start of the experiment and the other that takes the bottom of the baseline displacement as the zero point. The detectors in the smoke layer did not show baseline displacements. The predicted trend of the $\mathrm{CO}$ volume fraction in the smoke layer follows the measurements for both heights. The predicted trend for the ceiling jet follows the measurements for the $2.19 \mathrm{~m}$ height but increases with a smaller slope for the 1.5 $\mathrm{m}$ height. The measured values for $\mathrm{CO}$ in the smoke layer agreed with the prediction but in the ceiling jet, the predicted values lay below the measured values with the magnitude of the discrepancy dependent on the amount of baseline shift. 
Comparisons using propane with the small burner at a fire size of $2.7 \mathrm{~kW}$ are given in figure 13 . There is a baseline displacement of $2 \times 10^{-6}$ in volume fraction for the detector in the ceiling jet and the comparisons given in the figure include the $2 \times 10^{-6}$ baseline shift. The predicted trend for the $\mathrm{CO}$ in the ceiling jet follows the experimental trend although in the layer, the measured trend does not follow the predicted trend. It is possible that the $\mathrm{CO}$ volume fraction in the layer is so small that the measurement is more noise than signal.

\section{Smoke Analysis}

Figures 14-16 display the comparisons between the measured smoke density and the calculated smoke density for the upper layer and the maximum value in the ceiling jet using JET. For the $2.5 \mathrm{~kW}$ fire, the predictions either lie below or between the predictions for the density in the layer and ceiling jet with the $2.19 \mathrm{~m}$ measurement showing a sudden increase in measured density at about $170 \mathrm{~s}$ into the experiment. This sudden increase in density was observed in the $7.6 \mathrm{~kW}$ experiment and could be a temperature problem with the diode detector or laser. The slope of the measured values did not agree with the calculated values for the $7.6 \mathrm{~kW}$ experiment but were much better for the $2.5 \mathrm{~kW}$ experiments. The measured values from the TEOM are consistently below the predicted values as demonstrated in figure 16. Measurements were not available for the smoke density in the layer.

\section{Radial Dependence Analysis}

The radial dependence of the ceiling jet algorithm was tested using CO detectors 3 and 5 . Detector 5 was located $60 \mathrm{~cm}$ from plume center and detector 3 was located $150 \mathrm{~cm}$ from plume center along the same radius. Based on the distance difference of the two detectors, detector 3 should give a signal 0.59 smaller than detector 5 if the radial decrease of the CO concentration in the ceiling jet follows equation 28 . Figures 17 and 18 compare the signal recorded by detector 3 with the signal from detector 5 multiplied by 0.59 for the $2.5 \mathrm{~kW}$ propene fires at $2.19 \mathrm{~m}$ and $1.5 \mathrm{~m}$ ceiling heights. The curves agree within the measurement uncertainty of the experiment that is estimated to be $1 \times 10^{-6}$ based on the uncertainty of the zero measurement for the two detectors. No correction was made for time of flight between the two detectors but if a correction were made the agreement would improve, as the curve for detector 3 would move to the left to compensate for the increased time for the hot gas to reach that detector.

\section{Conclusion}

Algorithms to predict gas and smoke concentrations in the plume and ceiling jet have been developed and tested against experiments. The zone model JET was modified to include the algorithms and was used to generate the model predictions. The comparison of prediction versus measurement for $\mathrm{CO}$ in the ceiling jet demonstrated the importance of including the detector response and the development time for the smoke layer in the calculations.

The $\mathrm{CO}$ sensing elements in the ceiling jet responded to the changing temperature of their environment by shifting the zero baseline at the start of the experiment. This shift in zero baseline introduced an uncertainty in the measured $\mathrm{CO}$ volume fraction that was more pronounced for propane with its low level of $\mathrm{CO}$ production and for the $7.6 \mathrm{~kW}$ propene 
experiments with their higher temperatures. It would be desirable to measure the $\mathrm{CO}$ volume fraction by an independent method to check the consistency of this measurement.

The experiments used for the comparison of the algorithm predictions with the smoke concentration measurements bear repeating. The discrepancy in the smoke concentration measurements using the TEOM and laser attenuation also needs to be investigated. The smoke concentration values provided by the TEOM were lower than expected. The laser signals were noisy which made it difficult to determine whether the laser optics were being coated by smoke during the experiment. The impact of temperature effecting the laser measurements also needs to be investigated.

Additional measurements of the smoke, $\mathrm{CO}$, and temperature as a function of depth need to be done in order to verify that the structure of the ceiling jet is similar to the structure determined by temperature measurements.

In summary, ceiling jet algorithms have been developed for predicting smoke and $\mathrm{CO}$ concentrations in the presence of a growing layer. These algorithms can be used with appropriate detector algorithms to predict the activation of smoke and $\mathrm{CO}$ detectors located in the ceiling jet. The new algorithms have been incorporated in the zone model JET and will become available when the next version of JET is released. 
1. Alpert, R., L., "Calculation of Response Time of Ceiling-Mounted Fire Detectors", Fire Technology, 8, 1972, pp. 181-195.

2. Evans, D. D., and Stroup, D. W., "Methods to Calculate the Response Time of Heat and Smoke Detectors Installed below Large Unobstructed Ceilings", Fire Technology, 22, 1985, pp. 54-63.

3. Heskestad, G., and Delichatsios, M. A., "Environments of Fire Detectors Phase 1; Effects of Fire Size, Ceiling Height and Material, Volume II - Analysis", Technical Report Serial No. 22427, RC 77-T-11. Factory Mutual Research Corporation, 1977, pp. 1-100.

4. Davis, W. D., and Notarianni, K. A., "NASA Fire Detector Study", NISTIR 5798, National Institute of Standards and Technology, 1996, pp. 1-33.

5. Klote, J., Davis, W. D., Forney, G. P., and Bukowski, R., "Field Modeling; Simulating the Effects of HVAC induced Air Flow from Various Diffusers and Returns on Detector Response, Year Four Report", National Fire Protection Research Foundation, 1998.

6. Alpert, R. L., "Turbulent Ceiling-Jet Induced by Large-Scale Fires", Combustion Science and Technology, 1975, pp.197-213.

7. Yamauchi, Yukio, "Prediction of Response Time of Smoke Detectors in Enclosure Fires", National Institute of Standards and Technology, a NBSIR88-3707, 1988, pp. 146.

8. Heskestad, G., "Engineering Relations for Fire Plumes," Fire Safety J., 7, 1984, pp. 2532.

9 Tewarson, A., "Generation of Heat and Chemical Compounds in Fires," The SFPE Handbook of Fire Protection Engineering, NFPA, 1995, pp. 3-53 - 3-124.

10. Mulholland, G. W. and Croarkin, C., "Specific Extinction Coefficient of Flame Generated Smoke", Fire and Materials, 24, 2000, pp. 227-230.

11. Zukoski, E. E., Kubota, T., and Cetegen, B., "Entrainment in Fire Plumes", Fire Safety Journal, 3, 1981, pp. 107-121.

12. Grosshandler, W. "Toward the Development of a Universal Fire Emulator-Detector Evaluator," Fire Safety J., 29, 1997, pp. 113 - 128.

13. Newman, J. S., and Steciak, J., "Characterization of Particulates from Diffusion Flames", Combustion and Flame, 67, 1987, pp.55-64. 
14. Kounalakis, M. E., Sivathanu, Y. R., and Faeth, G. M., "Structure and radiation Properties of Turbulent Nonluminous and Luminous Diffusion Flames", NIST Grant 60nanb5d0576.BU, 1988, pp.1-78.

15. Orloff, L., de Ris, J. and Delichatsios, M. A., "Radiation From Buoyant Turbulent Diffusion Flames", Factory Mutual Research Corporation FMRC J.I. OTOJ7.BU, 1991, pp.1-16.

16. Becker, H. A. and Liang, D., "Total Emission of Soot and Thermal Radiation by Free Turbulent Diffusion Flames", Combustion and Flame, 44, 1982, pp. 305-318.

17. Davis, W. D., "The Zone Fire Model JET: A Model for the Prediction of Detector Activation and Gas Temperature in the Presence of a Smoke Layer", NISTIR 6324, National Institute of Standards and Technology, 1999, pp. 1-51.

18. Cleary, T., Hellerman, S., and Davis, W. D., "Response functions and Velocity Dependence for Smoke and CO Detectors", to be published as a NISTIR. 


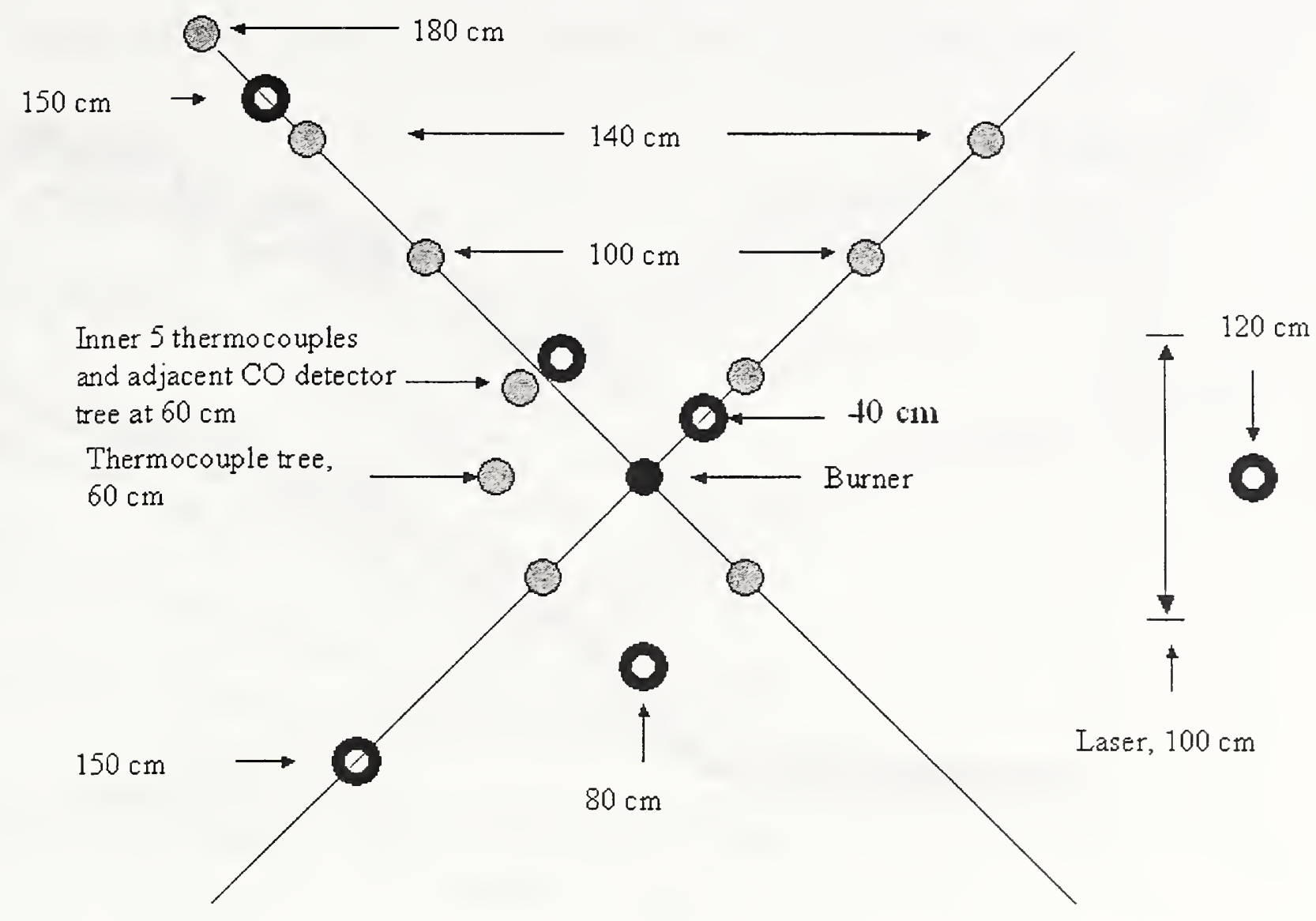

Figure 1 Detector locations for the experiments. The solid circles are thermocouples, the rings are $\mathrm{CO}$ detectors, and the location of the laser beam is shown on the right. The TEOM inlet was located just below the laser beam at $100 \mathrm{~cm}$ from the burner. The $\mathrm{CO}$ detector tree consisted of a detector in the ceiling jet with additional detectors located at $1 / 3$ and $2 / 3$ the distance between the burner and the ceiling. The thermocouple tree had thermocouples located at $(1,3,6,12,24$, $36,50,75$, and 100$) \mathrm{cm}$ below the ceiling. 


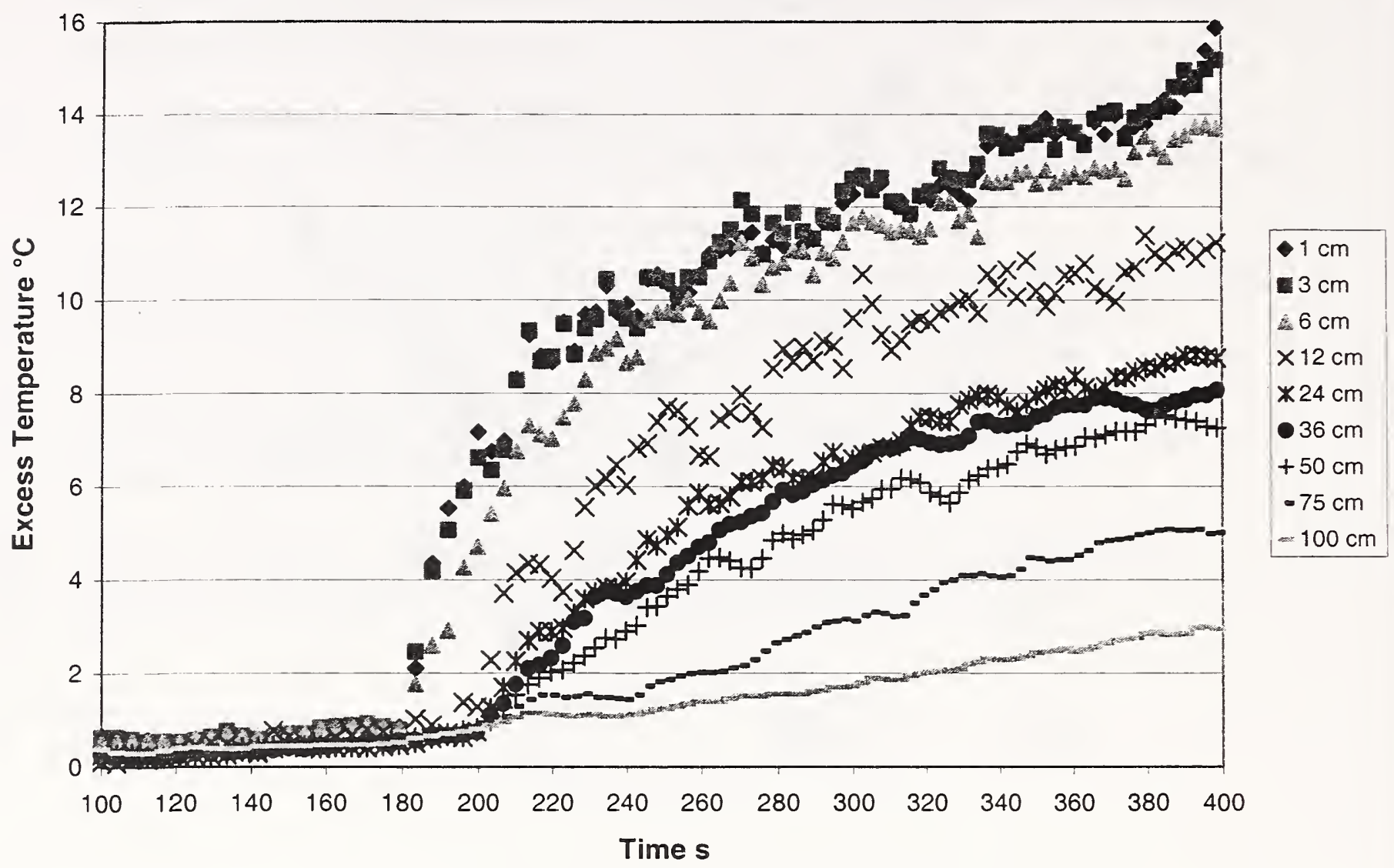

Figure 2 Excess temperature measurements for propene at $60 \mathrm{~cm}$ from the axis of the small burner (flow rate of $2.0 \mathrm{~L} / \mathrm{min}$ ) that was located $1.5 \mathrm{~m}$ below the ceiling. 


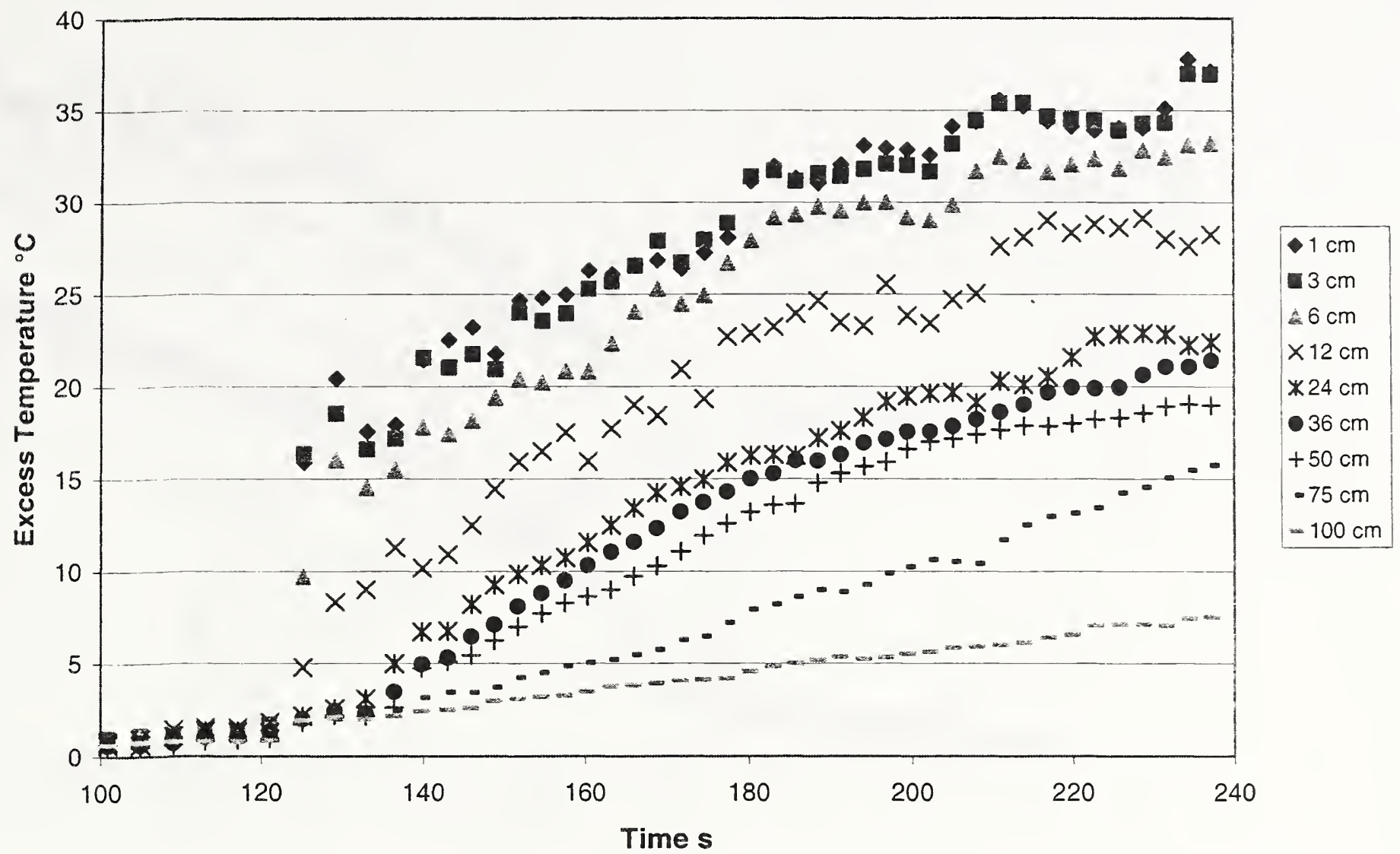

Figure 3 Excess temperature measurements for propene at $60 \mathrm{~cm}$ from the axis of the large burner (flow rate of $6.0 \mathrm{~L} / \mathrm{min}$ ) that was located $1.5 \mathrm{~m}$ below the ceiling. 


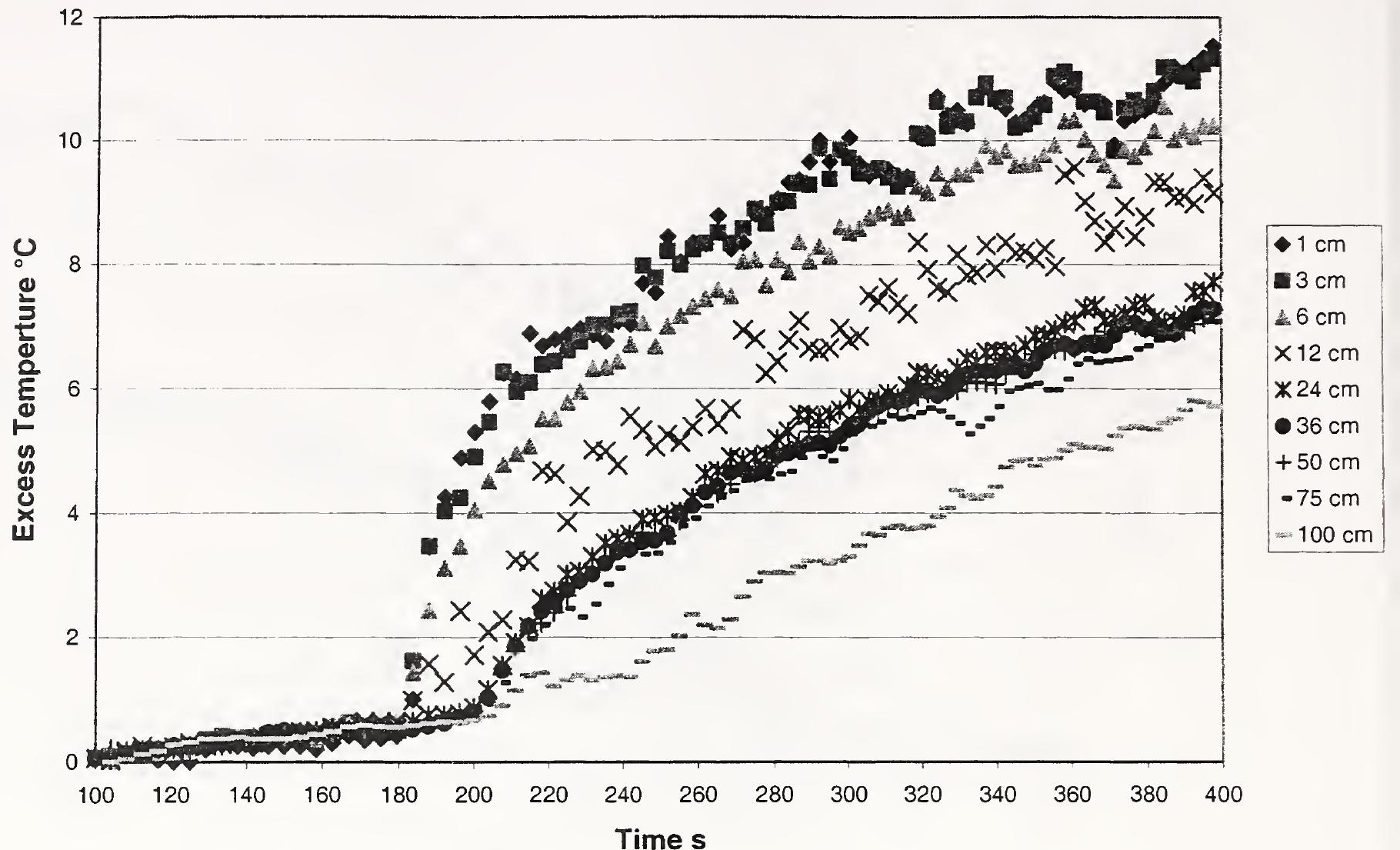

Figure 4 Excess temperature measurements for propene at $60 \mathrm{~cm}$ from the axis of the small burner (flow rate of $2.0 \mathrm{~L} / \mathrm{min}$ ) that was located $2.19 \mathrm{~m}$ below the ceiling. 


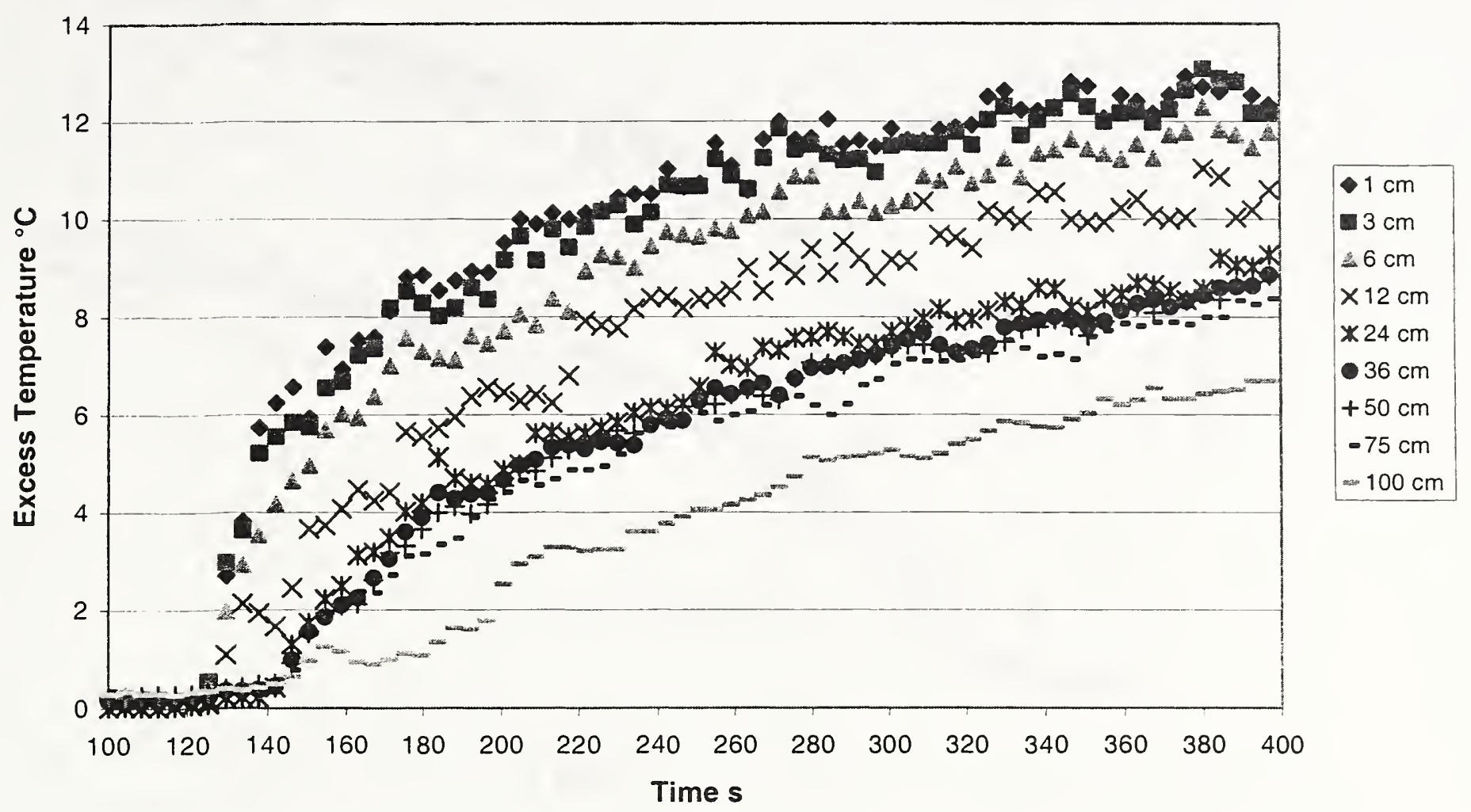

Figure 5 Excess temperature measurements for propane at $60 \mathrm{~cm}$ from the axis of the small burner (flow rate of $1.88 \mathrm{~L} / \mathrm{min}$ ) that was located $2.19 \mathrm{~m}$ below the ceiling. 


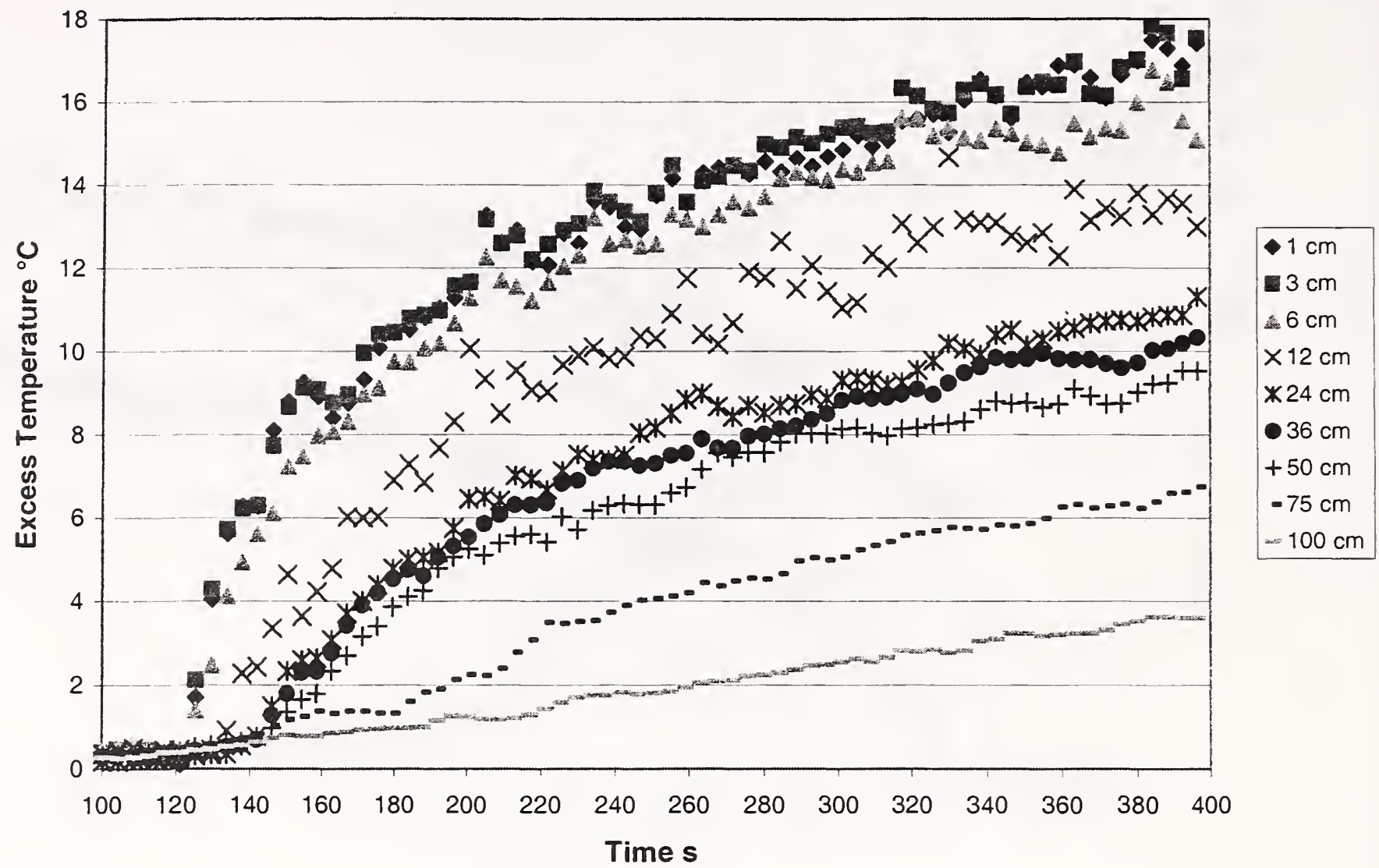

Figure 6 Excess temperature measurements for propane at $60 \mathrm{~cm}$ from the axis of the small burner (flow rate of $1.88 \mathrm{~L} / \mathrm{min}$ ) that was located $1.5 \mathrm{~m}$ below the ceiling. 


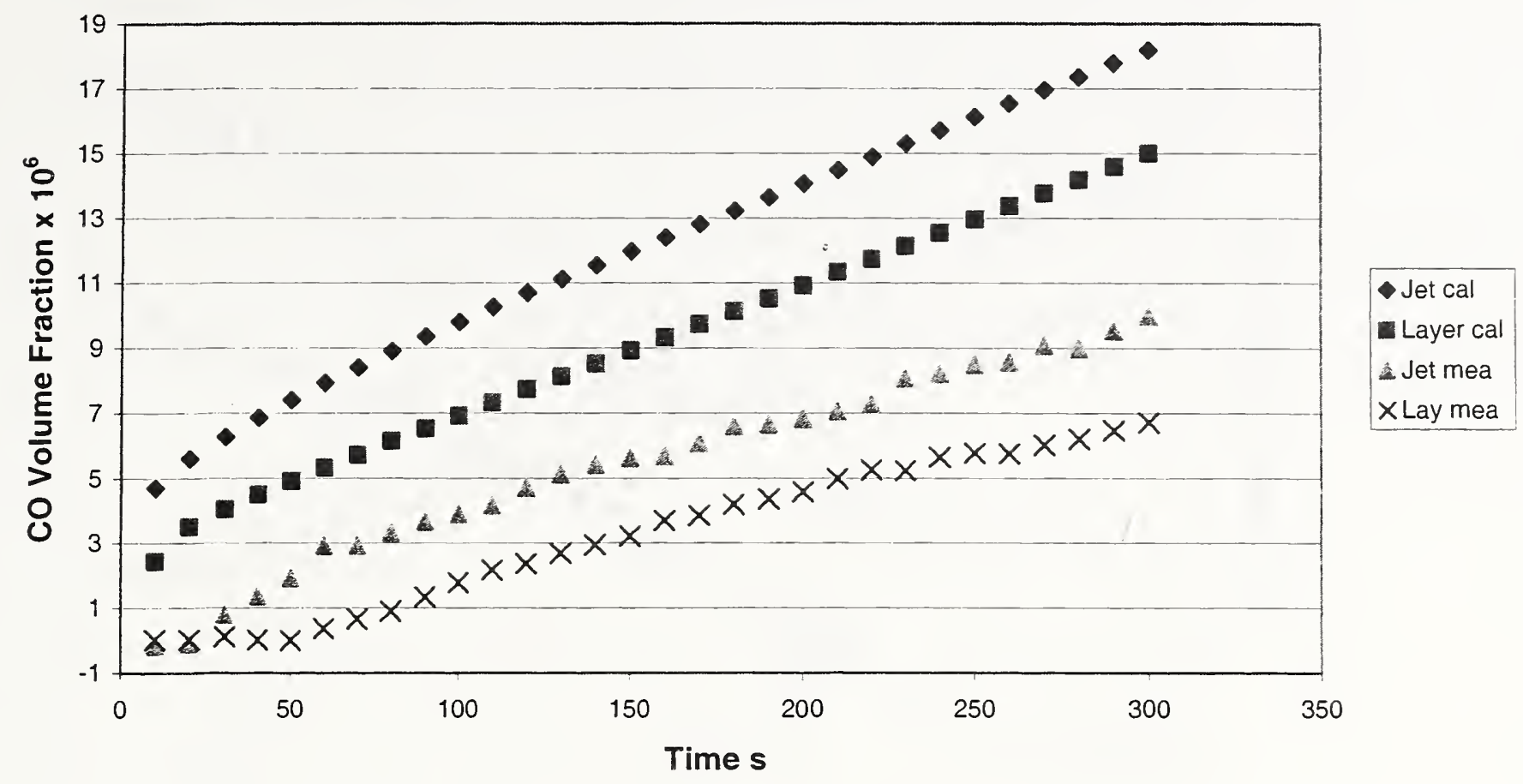

Figure 7 Comparison of measured and calculated $\mathrm{CO}$ volume fraction for the $2.5 \mathrm{~kW}$ small burner experiment at a height of $2.19 \mathrm{~m}$. Delay times and detector response functions are not included in the calculation. 


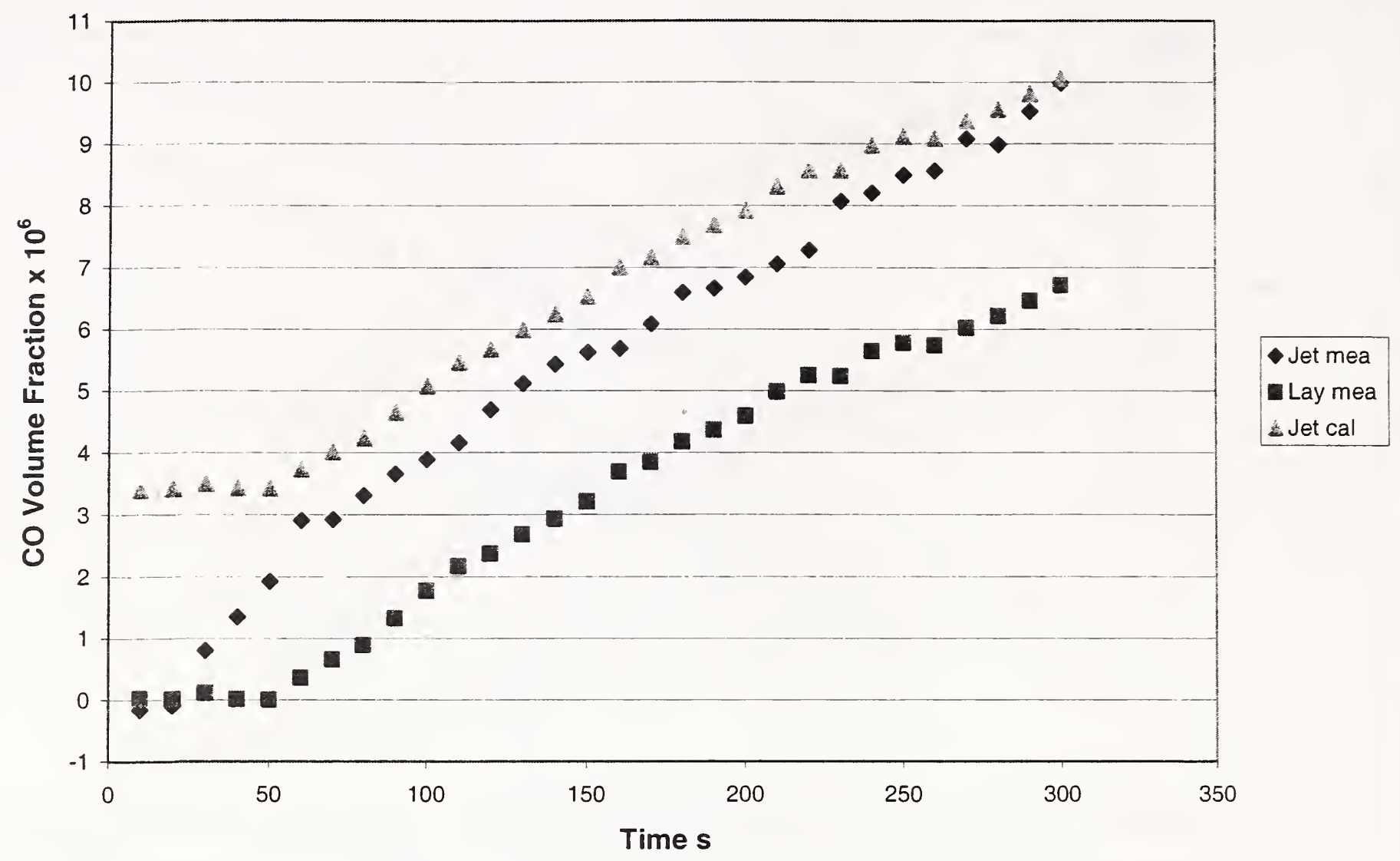

Figure $8 \mathrm{CO}$ volume fraction measured in the ceiling jet and layer (mea) and calculated for the ceiling jet (cal). The fire was propene at $2.5 \mathrm{~kW}$ (small burner) with the top of the burner located $2.19 \mathrm{~m}$ beneath the ceiling. The measured value of the $\mathrm{CO}$ volume fraction was used in the calculation of the ceiling jet molar fraction. 


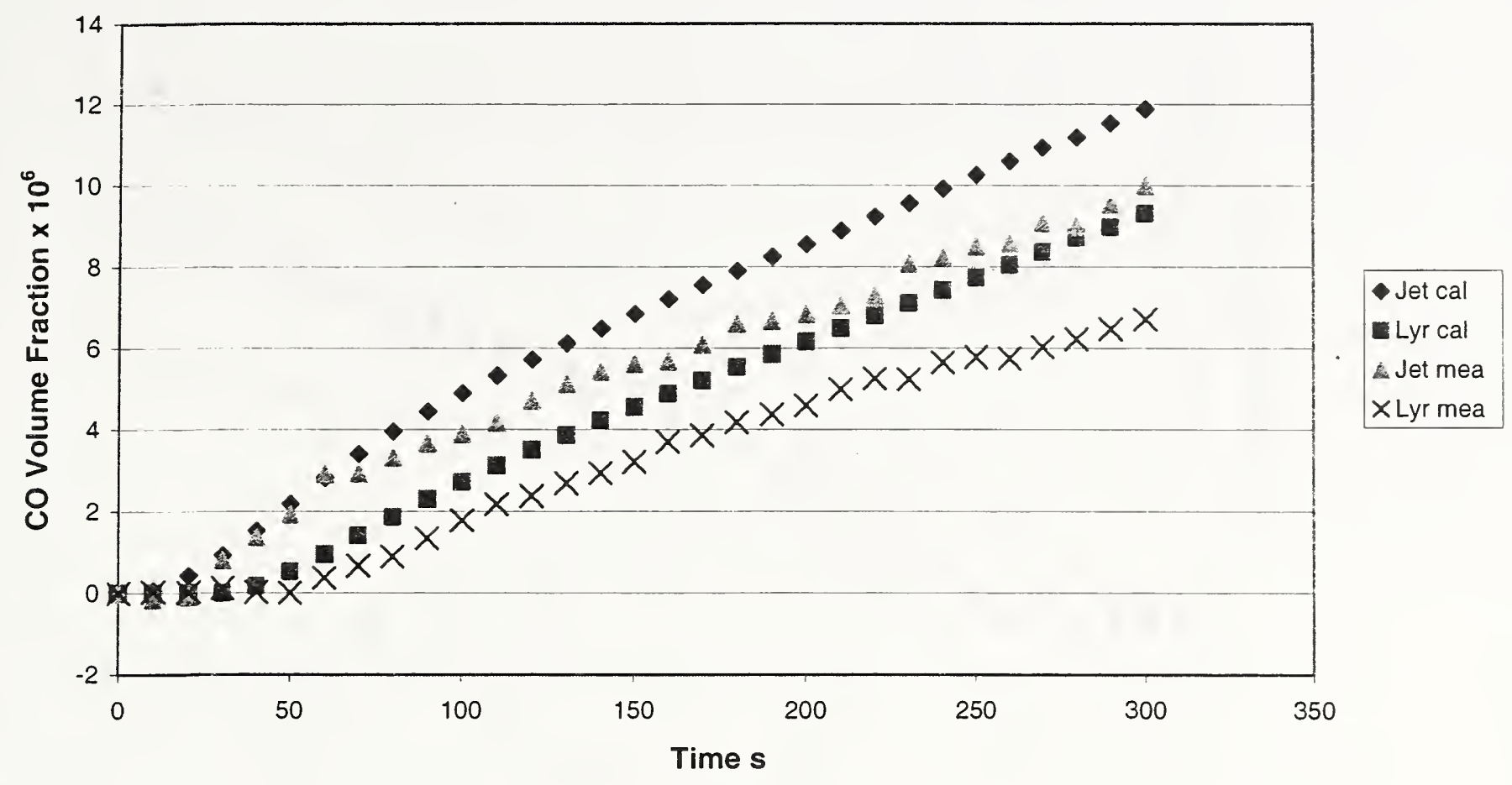

Figure $9 \mathrm{CO}$ volume fraction measured in the ceiling jet and layer (mea) and calculated for the ceiling jet (cal). The fire was propene at $2.5 \mathrm{~kW}$ (small burner) with the top of the burner located $2.19 \mathrm{~m}$ beneath the ceiling. Ceiling jet transit time, layer formation delay time and detector response characteristics are included in the calculations. 


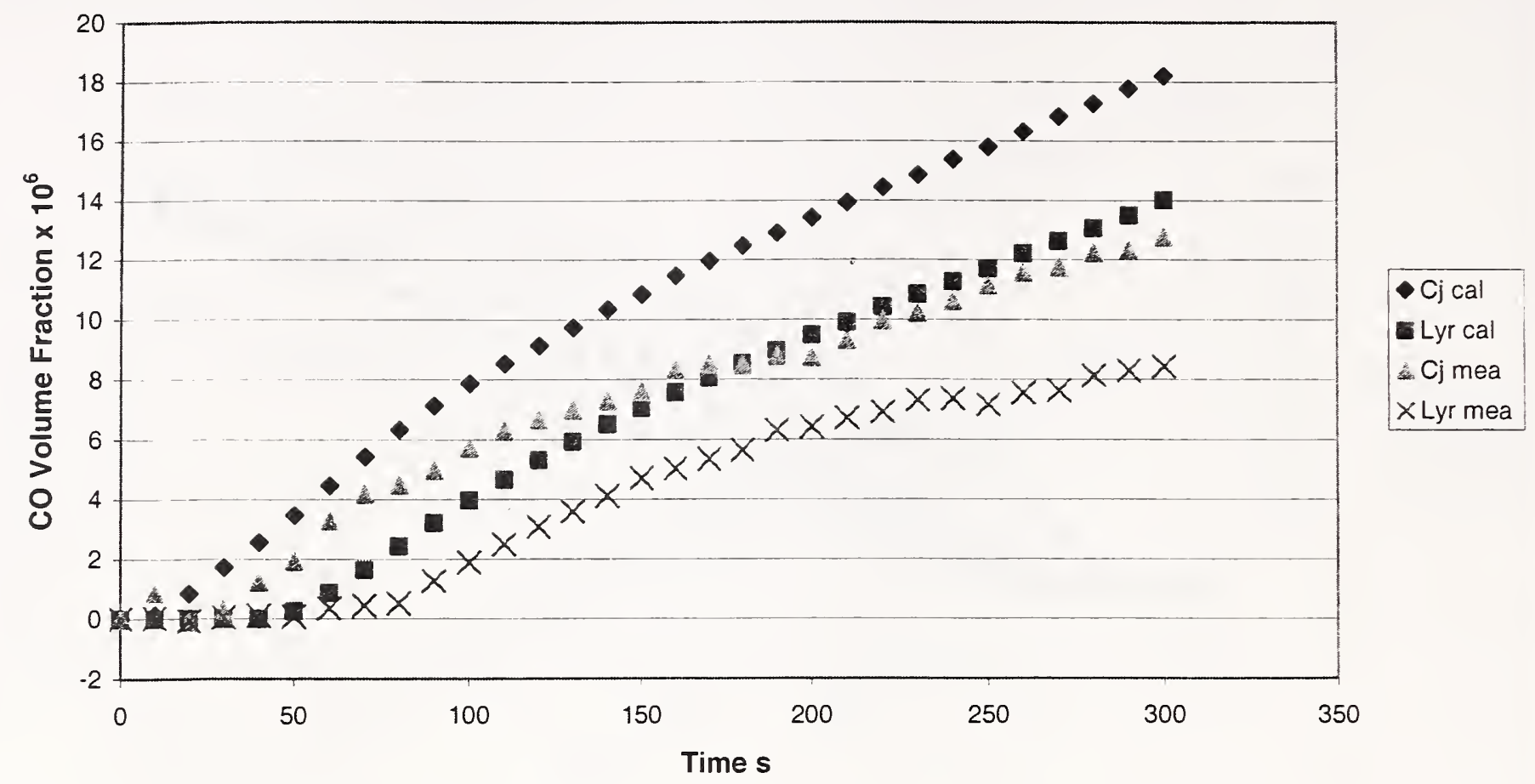

Figure $10 \mathrm{CO}$ volume fraction measured in the ceiling jet and layer (mea) and calculated for the ceiling jet (cal). The fire was propene at $2.5 \mathrm{~kW}$ (small burner) with the top of the burner located $1.5 \mathrm{~m}$ beneath the ceiling. Ceiling jet transit time, layer formation delay time and detector response characteristics are included in the calculations. 


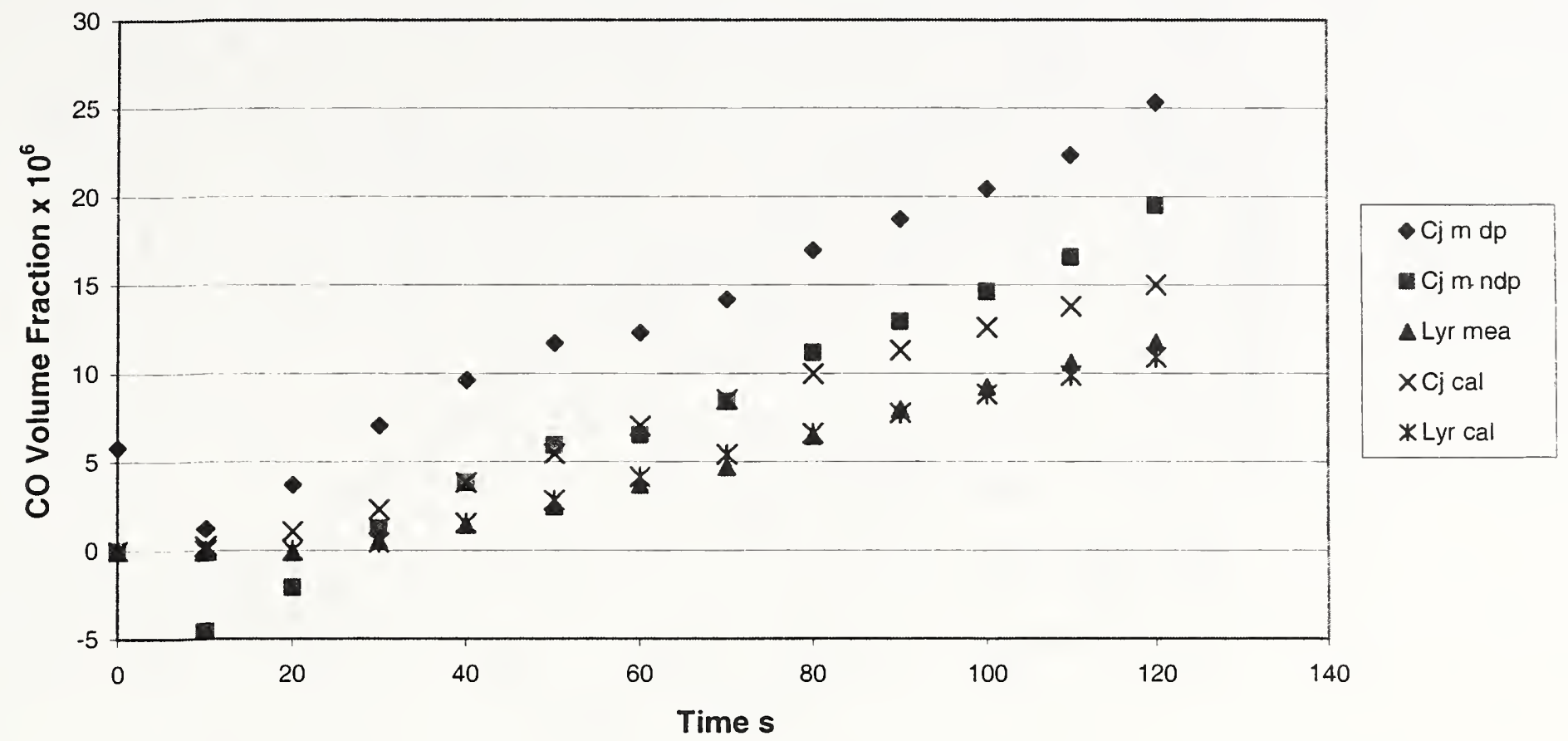

Figure $11 \mathrm{CO}$ volume fraction measured in the ceiling jet and layer ( $\mathrm{m}$ and mea) and calculated for the ceiling jet and layer (cal). The ceiling jet measurements are plotted using the zero baseline as the bottom of the signal dip (dp) and as the baseline at the start of the experiment (ndp). The fire was propene at $7.6 \mathrm{~kW}$ (large burner) with the top of the burner located $2.19 \mathrm{~m}$ beneath the ceiling. Ceiling jet transit time, layer formation delay time and detector response characteristics are included in the calculations. 


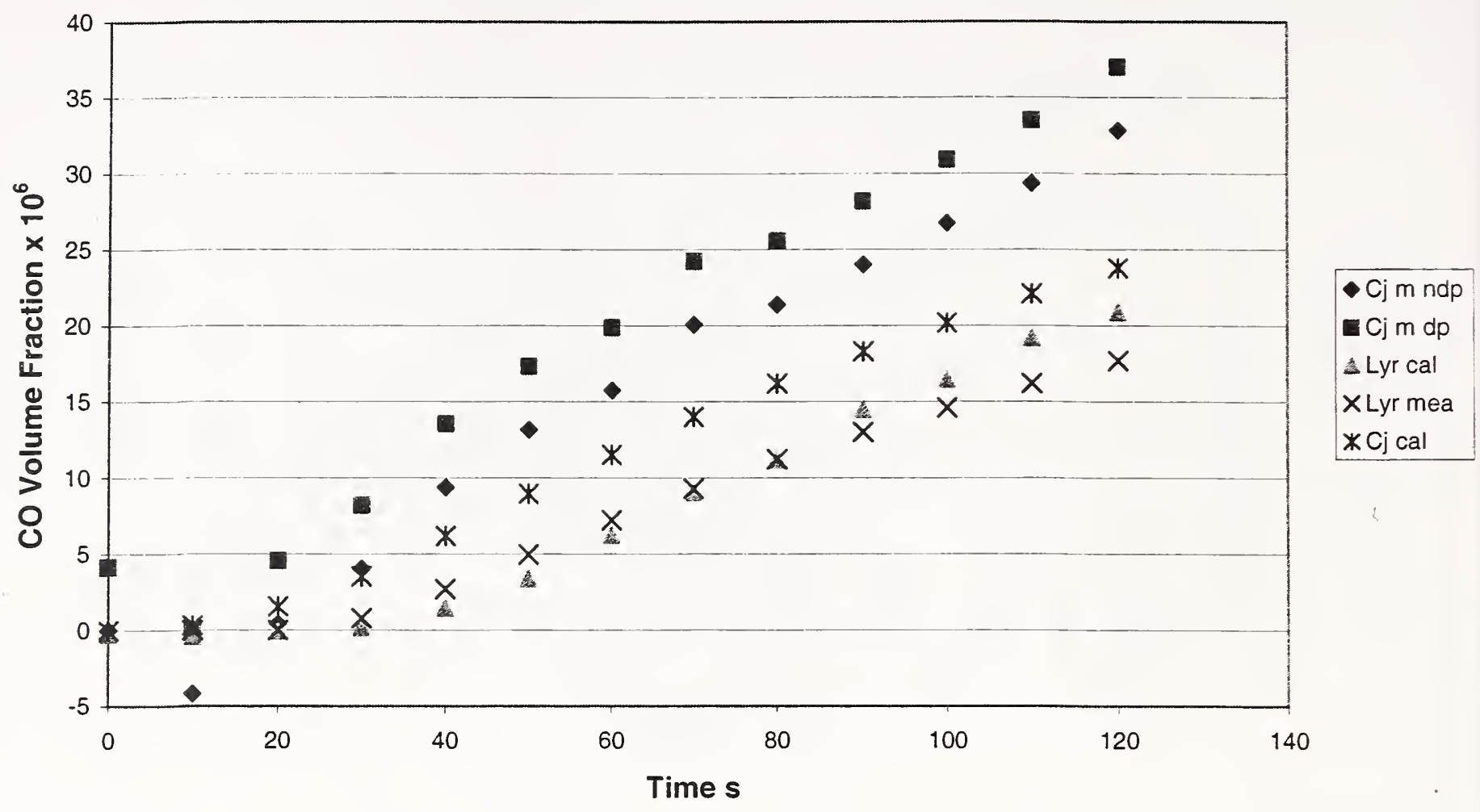

Figure $12 \mathrm{CO}$ volume fraction measured in the ceiling jet and layer ( $\mathrm{m}$ and mea) and calculated for the ceiling jet (cal). The ceiling jet measurements are plotted using the zero baseline as the bottom of the signal dip (dp) and as the baseline at the start of the experiment (ndp). The fire was propene at $7.6 \mathrm{~kW}$ (large burner) with the top of the burner located $1.5 \mathrm{~m}$ beneath the ceiling. Ceiling jet transit time, layer formation delay time and detector response characteristics are included in the calculations. 


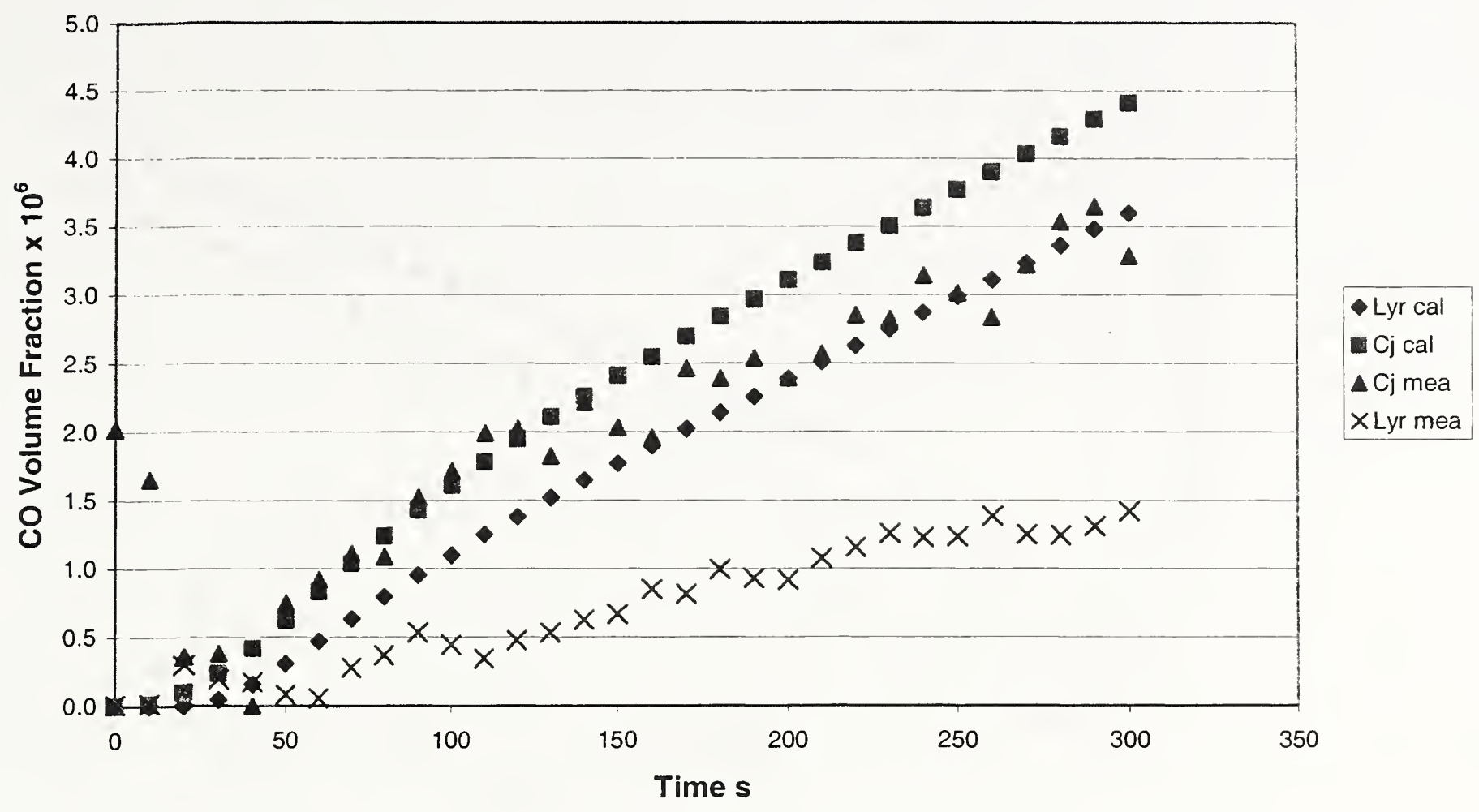

Figure $13 \mathrm{CO}$ volume fraction measured in the ceiling jet and layer (mea) and calculated for the ceiling jet (cal). The fire was propane at $2.7 \mathrm{~kW}$ (small burner) with the top of the burner located $2.19 \mathrm{~m}$ beneath the ceiling. Ceiling jet transit time, layer formation delay time and detector response characteristics are included in the calculations. 


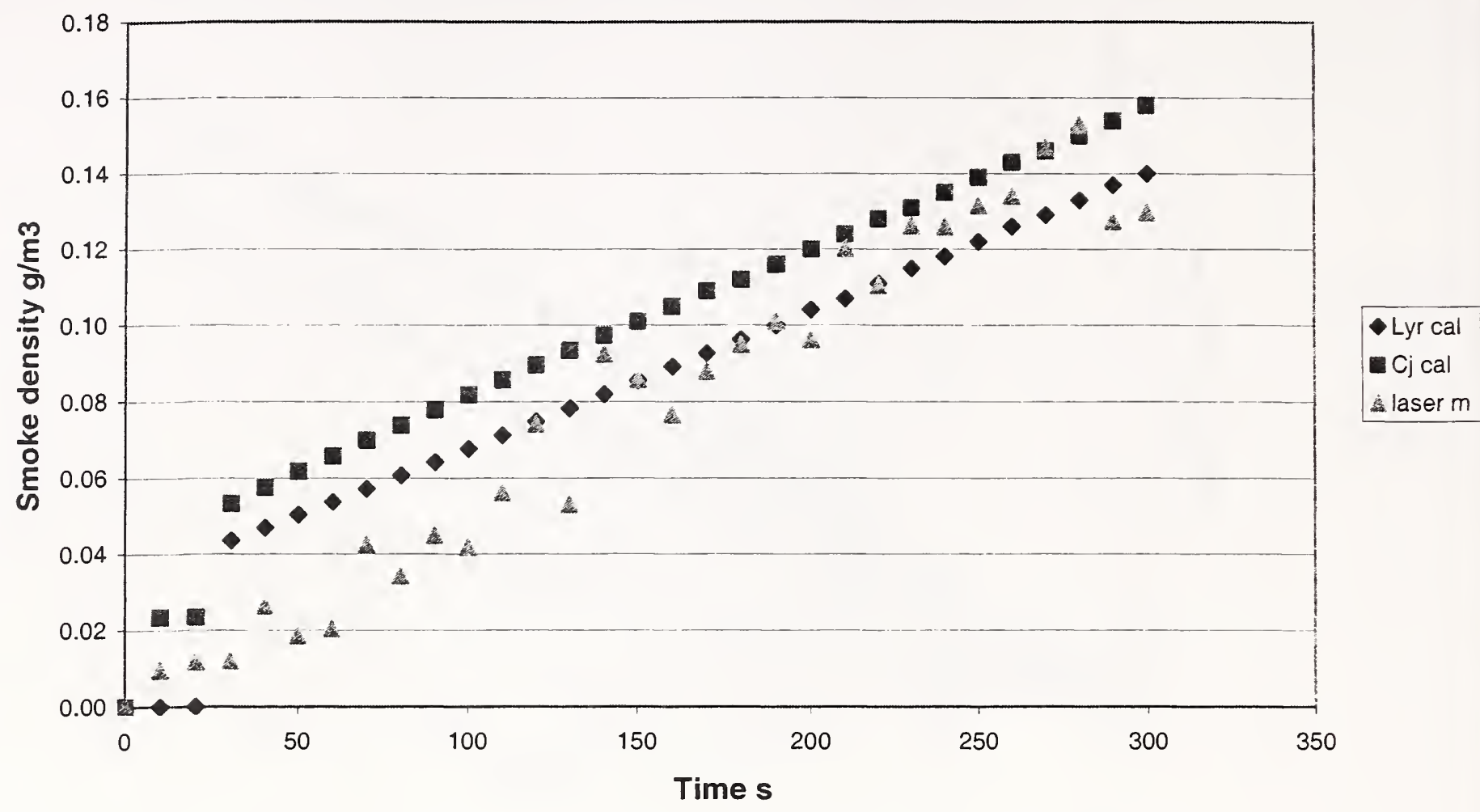

Figure 14 Smoke density measured in the ceiling jet (laser $\mathrm{m}$ ) and calculated for the ceiling jet (CJ cal) and smoke layer (Lyr cal). The fire was propene at $2.5 \mathrm{~kW}$ (small burner) with the top of the burner located $1.5 \mathrm{~m}$ beneath the ceiling. Ceiling jet transit time and layer formation delay time are included in the calculations. 


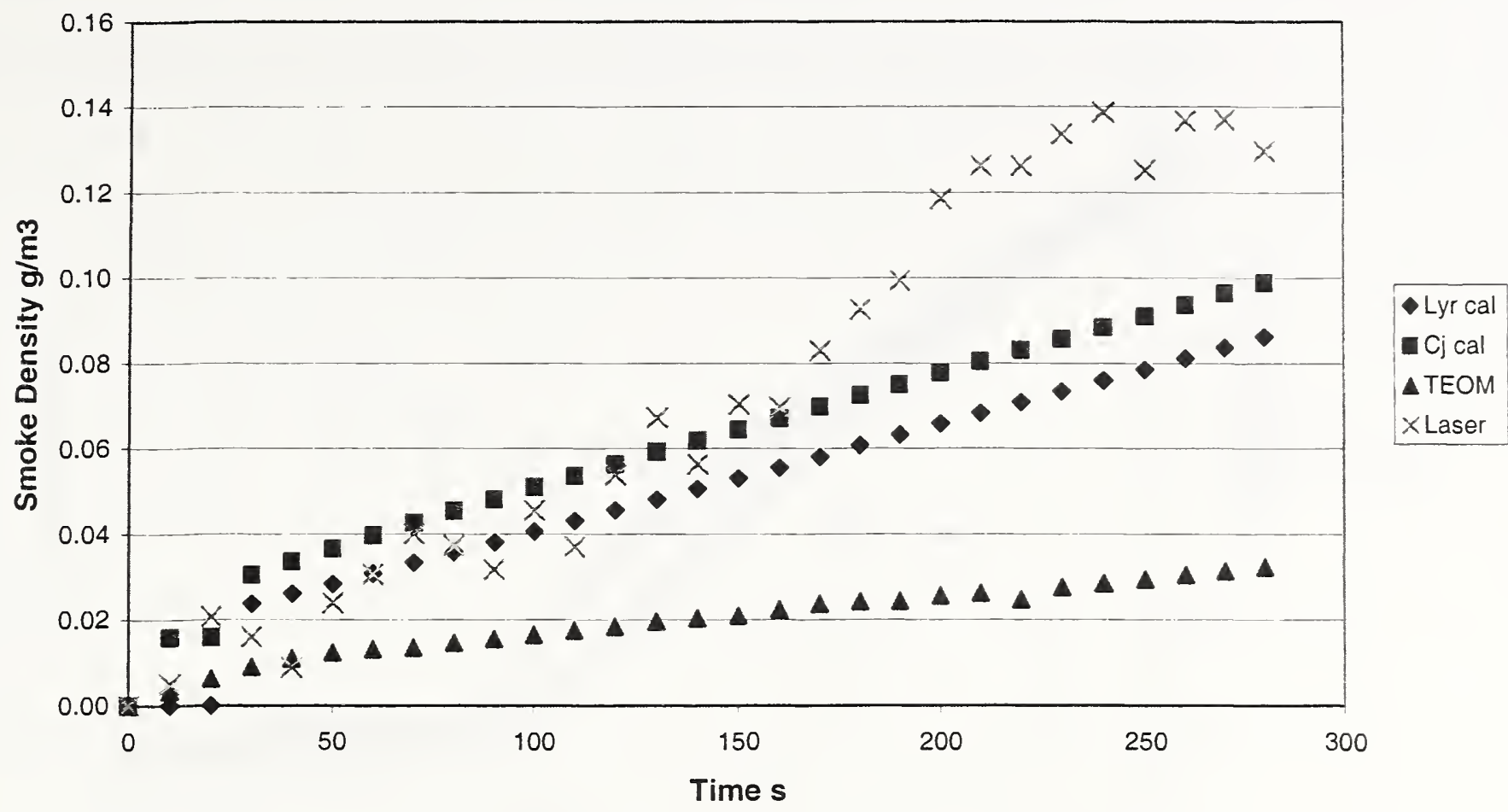

Figure 15 Smoke density measured in the ceiling jet (laser and TEOM) and calculated for the ceiling jet (CJ cal) and smoke layer (Lyr cal). The fire was propene at $2.5 \mathrm{~kW}$ (small burner) with the top of the burner located $2.19 \mathrm{~m}$ beneath the ceiling. Ceiling jet transit time and layer formation delay time are included in the calculations. 


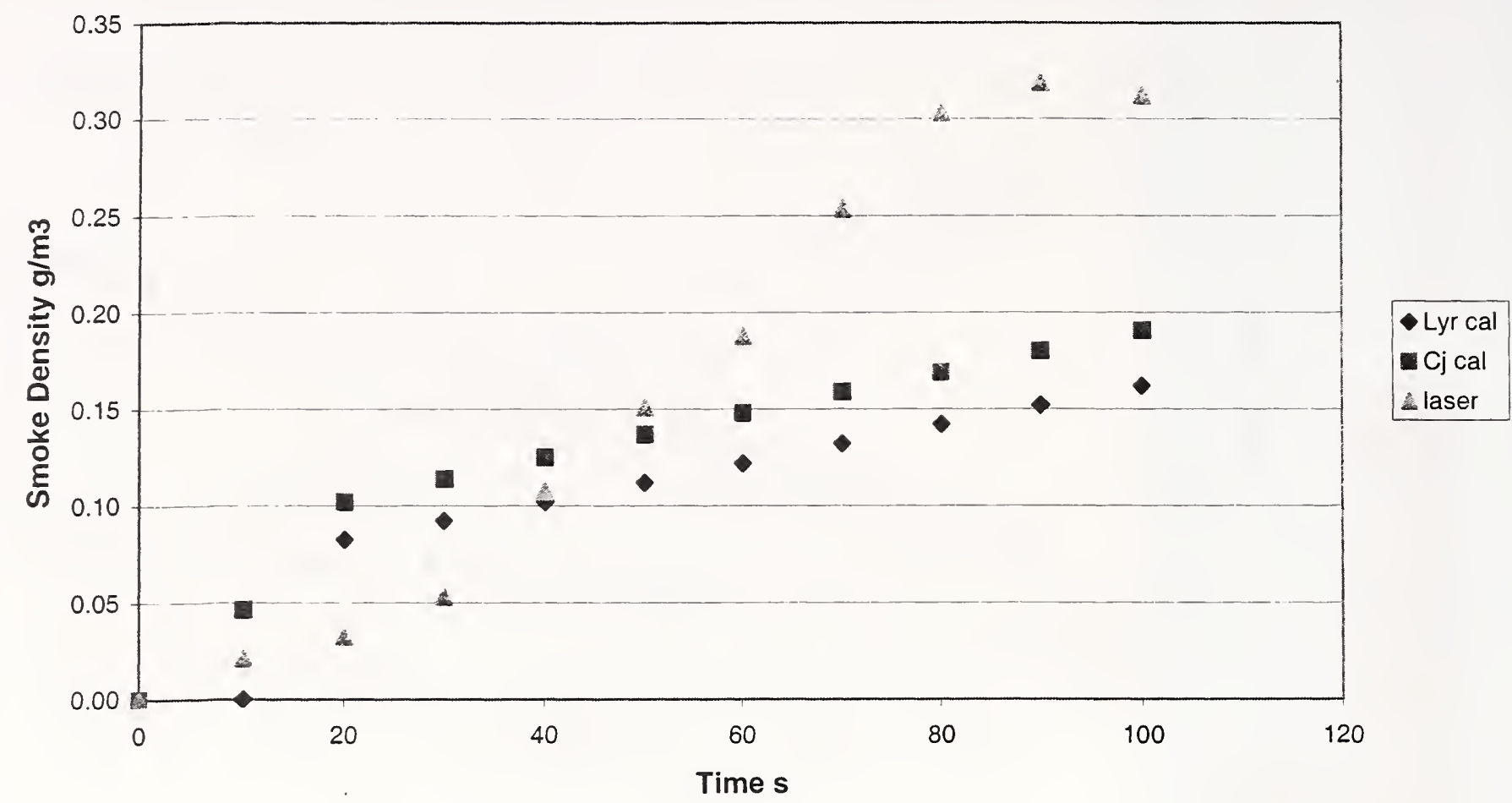

Figure 16 Smoke density measured in the ceiling jet (laser $\mathrm{m}$ ) and calculated for the ceiling jet (Cj cal) and smoke layer (Lyr cal). The fire was propene at $7.6 \mathrm{~kW}$ (small burner) with the top of the burner located $1.5 \mathrm{~m}$ beneath the ceiling. Ceiling jet transit time and layer formation delay time are included in the calculations 


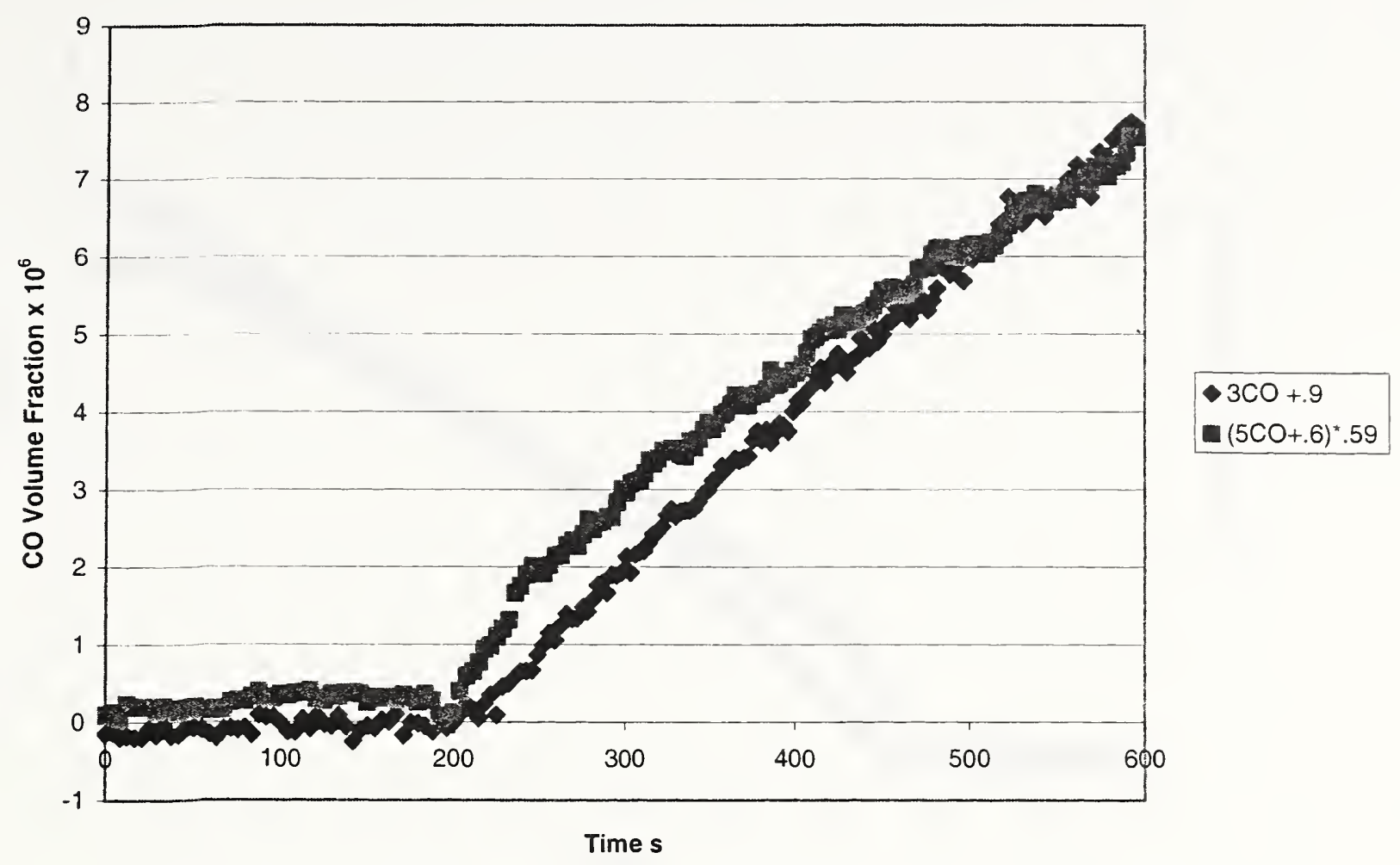

Figure 17 Radial dependence comparison using $\mathrm{CO}$ detectors 5 and 3 located in the ceiling jet at $60 \mathrm{~cm}$ and $150 \mathrm{~cm}$ respectively. Detector 5 has had its zero corrected by 0.6 and is scaled to 0.59 which is the predicted scaling by the ceiling jet algorithm. A $2.5 \mathrm{~kW}$ propene fire was used (small burner) at a distance $2.19 \mathrm{~m}$ below the ceiling. 


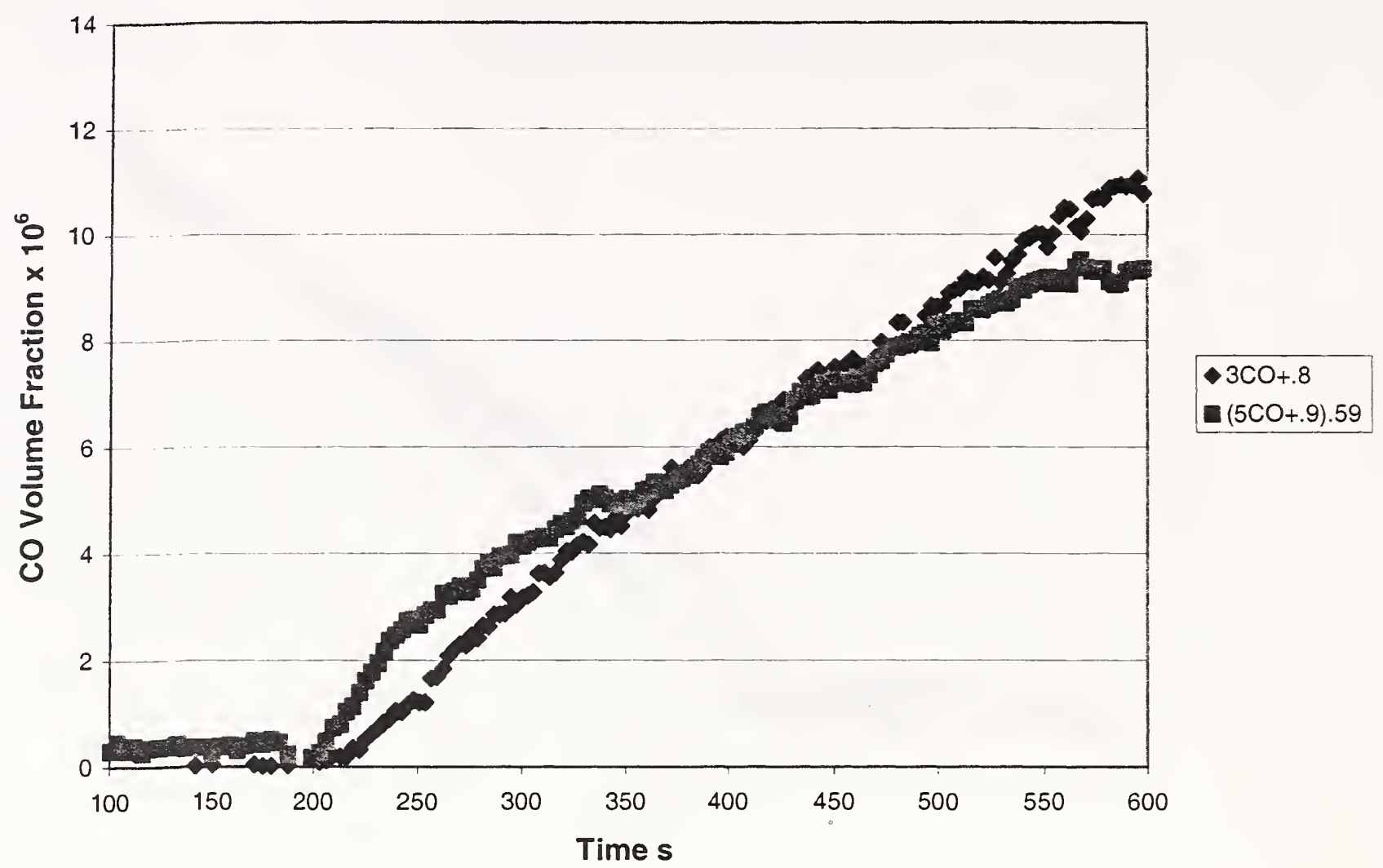

Figure 18 Radial dependence comparison using $\mathrm{CO}$ detectors 5 and 3 located in the ceiling jet at $60 \mathrm{~cm}$ and $150 \mathrm{~cm}$ respectively. Detector 5 has had its zero corrected by 0.6 and is scaled to 0.59 which is the predicted scaling by the ceiling jet algorithm. A $2.5 \mathrm{~kW}$ propene fire was used (small burner) at a distance $1.5 \mathrm{~m}$ below the ceiling. 



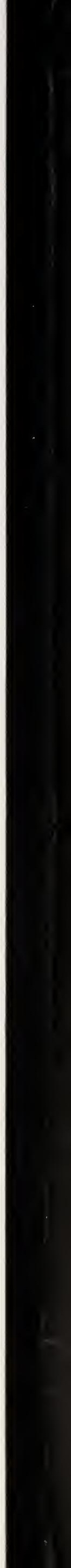

